\title{
PARTIDOS Y SISTEMA DE PARTIDOS EN LAS ELECCIONES MEXICANAS DE $2018^{1}$
}

\author{
PARTIES AND THE PARTY SYSTEM \\ IN THE 2018 MEXICAN ELECTIONS
}

\author{
LES PARTIS ET LE SYSTÈME DE PARTIS \\ DANS LES ÉLECTIONS DE 2018 AU MEXIQUE
}

\author{
Jean-François Prud'homme \\ El Colegio de México \\ jfprud@colmex.mx
}

\begin{abstract}
Resumen: Este artículo analiza los cambios que afectaron a los partidos y al sistema de partidos mexicanos durante el sexenio del presidente Enrique Peña Nieto. Durante el periodo 2012-2018, asistimos a la erosión y, posteriormente, al derrumbe del sistema de tres grandes partidos, formado y consolidado durante el proceso de apertura política en México. Esa transformación puede apreciarse a partir de la evolución de las preferencias electorales, las crisis internas de los partidos y las modificaciones a la legislación electoral.

Palabras clave: México-partidos políticos; México-sistema de partidos; México-elecciones 2012-2018.
\end{abstract}

Aвstract: This paper analyses the changes that affected the Mexican political parties and the party system during President Enrique Peña Nieto's six-year term in office. Between 2012-2018, we witnessed the erosion and subsequent collapse of the system of three major parties that had been formed and consolidated during the process of political liberalization in Mexico. This transformation may be observed in the evolution of electoral preferences, the internal crises of the parties, and in changes to electoral legislation.

${ }^{1}$ Agradezco el apoyo inicial de Fernando Luna y, posteriormente, de Julio César González para la recopilación del material hemerográfico y la elaboración de los cuadros y gráficas. 
Keywords: Mexico - political parties; Mexico - party system; Mexico elections 2012-2018.

\section{Traducción de Gonzalo Celorio Morayta}

RÉsumÉ: L'article analyse les changements subis par le système de partis politiques et par ceux-ci, à titre individuel, sous le gouvernement du président Enrique Peña Nieto. Dans la période 2012-2018 on a assisté à l'érosion, puis à l'effondrement de l'appareil tripartite qui s'était formé et consolidé lors du processus d'ouverture politique. Cette transformation s'est manifestée par l'évolution des préférences électorales, les crises internes des partis et la réforme des lois concernant les élections.

Mots clefs: Mexique - partis politiques; Mexique - système de partis;

Mexique - élections 2012-2018.

Traducción de Bernardo Mabire

Fecha de recepción: junio de 2019

Fecha de aceptación: noviembre de 2019 
$\mathrm{E}$ 1 sexenio del presidente Enrique Peña Nieto marcó un cambio profundo en el sistema de partidos y la representación política en México. Entre 2012 y 2018, al filo de las distintas elecciones locales y nacionales, se erosionó el sistema multipartidista anclado en tres grandes partidos (Partido Acción Nacional, PAN; Partido de la Revolución Democrática, PRD, y Partido Revolucionario Institucional, PRI) que se consolidó en la última década del siglo xx y fue el eje del cambio institucional de los últimos treinta años. Entre las razones que contribuyen a explicar ese cambio están: 1) la evolución de las preferencias electorales; 2) las crisis internas experimentadas en el PRD y el PAN y la creciente insatisfacción con el gobierno del presidente Peña Nieto (PRI); 3) los cambios en la legislación electoral.

Siguiendo a Peter Mair ${ }^{2}$ en su discusión sobre la identificación del cambio en los sistemas de partidos, parto del principio de que se puede hablar de transformación cuando se pasa de una clase de sistema de partidos a otra. Para decirlo de manera más precisa, y retomando las dimensiones utilizadas por Giovanni Sartori, ${ }^{3}$ el cambio puede apreciarse a partir de alteraciones en el número de partidos relevantes y en el alcance de la polarización ideológica. Esas alteraciones terminan afectando la configuración del patrón de interacción entre partidos.

\section{A. Un Sistema "Á LA HUNTINGTON"}

Desde la instauración del primer sistema de partidos consolidado en México con la aprobación de la Ley Electoral Federal de 1946 prevaleció una concepción de la representación política asentada en la existencia de partidos que

${ }^{2}$ Peter Mair, Party System Change: Approaches and Interpretations, Oxford, Clarendon Press, 1998, pp. 51-52.

${ }^{3}$ Giovanni Sartori, Partidos y sistemas de partidos, Madrid, Alianza Editorial, 2005. 
constituían el principal vehículo de la participación. Si bien es cierto que el sistema de partidos que prevaleció hasta 1988 podía difícilmente ser calificado de competitivo y todavía menos de democrático, la figura del partido político como referente imaginario (o real) se colocaba en el centro de la legislación electoral y las sucesivas reformas consolidaron esa forma de la representación política: las candidaturas estaban atadas a la postulación por organizaciones partidistas, las organizaciones partidistas requerían un registro oficial, cuya consecución se asociaba a la satisfacción de una serie de requisitos entre los cuales se incluía la obligación de tener presencia nacional y la no reelección consecutiva de diputados y senadores, que favorecía el control de las dirigencias sobre las carreras políticas, entre otros. $\mathrm{Cu}-$ riosamente, dado que se trataba de instaurar y consolidar un sistema no competitivo, se asociaba la noción de partido a ideas de estabilidad, institucionalidad y educación del pueblo en una democracia incipiente. Esa noción recuerda el papel que Samuel Huntington atribuía a los partidos políticos en su obra El orden político en las sociedades en cambio: la existencia de partidos altamente institucionalizados, fueran uno o muchos, constituían una garantía de estabilidad política. ${ }^{4}$

Cuando a principios de los años 1990 se inició un ciclo de reformas político-electorales que pusieron paulatinamente fin al sistema de partido hegemónico con la introducción de un mayor grado de competencia interpartidista, se mantuvo esa concepción “à la Huntington” de los partidos y del sistema de partidos. ${ }^{5}$ Desde luego, hubo cambios cua-

${ }^{4}$ Samuel Huntington, Political Order in Changing Societies, New Haven y Londres, Yale University Press, 1969, pp. 89-90.

${ }^{5}$ Esa concepción de los partidos y del sistema de partidos no sólo respondía a una tradición nacional sino que concordaba con lo que la ciencia política de la tercera ola de democratización recomendaba para garantizar la estabilidad democrática. Remito al lector a Scott Mainwaring, Rethinking Party Systems in the Third Wave of Democratization: The Case of Brazil, Stanford, University Press, 1999. 
litativos en la naturaleza del sistema: se pasó de uno casi monopólico a una situación de control oligopólico de la representación, siguiendo un eje derecha-centro-izquierda, donde el Partido Acción Nacional (PAN), el Partido Revolucionario Institucional (PRI) y el Partido de la Revolución Democrática (PRD) constituían los pilares de la vida política. Si bien aparecieron y desaparecieron un número importante de pequeños partidos políticos, nunca constituyeron una amenaza para el predominio de los tres grandes partidos. Al filo de las sucesivas reformas electorales, se mantuvieron una serie de disposiciones, algunas heredadas del pasado, otras nuevas, que favorecían ese predominio: la obligación de ser postulado por un partido con registro para presentar candidaturas a cargos de elección popular, el requisito de tener presencia nacional para obtener el registro, la cláusula de no reelección consecutiva para diputados y senadores, la dificultad de crear y mantener nuevos partidos, la existencia de un generoso financiamiento público que favorecía a los partidos establecidos, el acceso a los medios, entre otras. Todas ellas estaban destinadas en principio a incrementar el grado de institucionalización de las organizaciones partidistas y del sistema de partidos, aun si la existencia de ese halo protector no garantizaba que los partidos estuvieran a la altura de esa concepción. Y si bien el PAN, el PRI y el PRD estaban en una situación de competencia real, terminaron compartiendo esa misma visión en el momento de aprobar reformas a las reglas electorales, manifestando así un fuerte "esprit de corps". 6

${ }^{6}$ Para un desarrollo más detallado del argumento, véase Jean-François Prud'homme, "El sistema de partidos", en Soledad Loaeza y JeanFrançois Prud'homme (coords.), Instituciones y procesos políticos, México, El Colegio de México, 2010, pp. 121-158. 


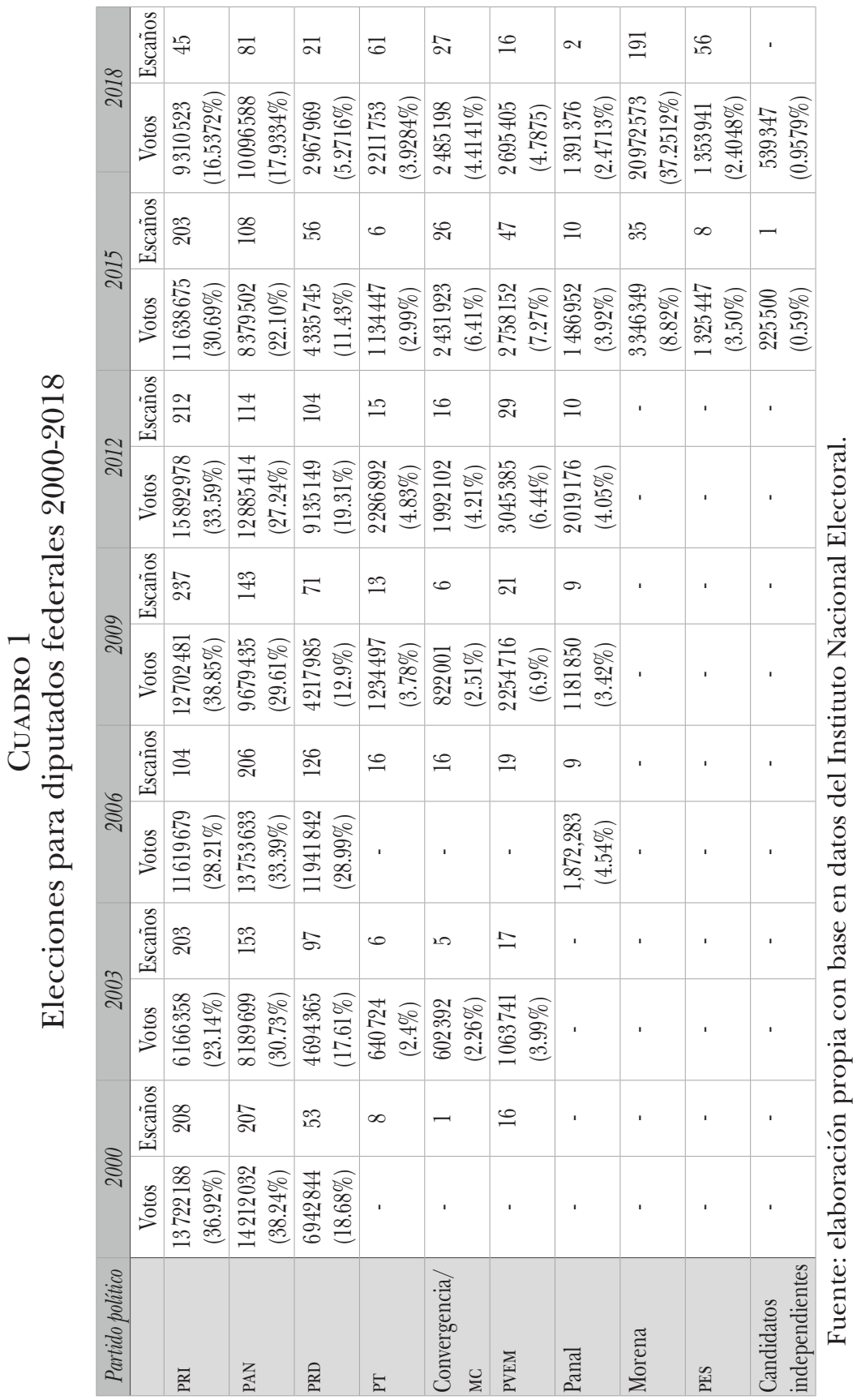


Entre 1991 y 2012, los tres grandes partidos reciben, elección federal tras elección federal, más del $80 \%$ de los votos y frecuentemente, $90 \%$. En lo que respecta a la representación en la Cámara de Diputados, la suma de los escaños obtenidos por esos partidos durante el mismo periodo representa más de $85 \%$ y hasta $97 \%$ del total de los escaños. Esa situación empezó a cambiar a raíz de las elecciones legislativas intermedias de 2015, en las cuales el trinomio PAN, PRI y PRD consiguió apenas más que el $61 \%$ de los votos, lo que se tradujo en una representación equivalente al $74 \%$ de los escaños en la Cámara de Diputados.

Sin embargo, detrás de esa aparente continuidad, ya estaban emergiendo indicadores de cambio relacionados con la capacidad de mantener el control oligopólico sobre las condiciones de la competencia interpartidista, así como con la diversificación de las preferencias electorales. En efecto, a pesar de que en la reforma electoral de 2007 se reforzaron las condiciones de acceso a la representación política para los partidos con menor apoyo electoral (PVEM, PT, Convergencia, Panal), estos últimos lograron mantener un nivel apreciable de diputados en el Congreso. ${ }^{7}$ Algo similar ocurrió en la reforma electoral de 2013-2014, cuando los partidos grandes impulsaron elevar el umbral de la representación de $2 \%$ a 3\% (y por lo tanto la conservación del registro). Por más que el objetivo fuera evitar la dispersión de la representación política, el resultado de las elecciones legislativas de 2015

${ }^{7}$ En esa reforma, se modificó la fórmula de repartición de los votos en los convenios de coalición de tal manera que se contabilizaran los votos efectivos recibidos por cada socio para definir el acceso a la representación y, en su caso, el número de diputados plurinominales al cual tendría derecho cada uno de ellos. Esa medida fue interpretada como un intento de dificultar la permanencia de las formaciones políticas con menor apoyo electoral. Jorge V. Alcocer, "La regulación de los partidos políticos”, Lorenzo Córdova y Pedro Salazar (coord.), Estudios sobre la reforma electoral 2007. Hacia un nuevo modelo, México, Tribunal Electoral del Poder Judicial de la Federación, 2008, pp. 320-321. A pesar de ello, sorprendió constatar que en las elecciones intermedias de 2009 esos partidos lograran mantener un caudal razonable de votos. 
permitió que dos partidos adicionales (Morena y Encuentro Social) accedieran a la Cámara de Diputados. ${ }^{8}$

De hecho, como bien lo destaca Sonnleitner, en el periodo que va de 2000 a 2015, el número de partidos efectivos se disparó pasando de un promedio de cerca de tres (con pequeños picos en elecciones intermedias) a casi seis (5.6) en 2015 para regresar a cuatro (4.4) en 2018. ${ }^{9}$ Así, podemos apreciar cómo los esfuerzos de las grandes formaciones políticas para mantener una mayor concentración de la representación política se enfrentan a tendencias electorales con efectos centrífugos.

Antes de cerrar este apartado, conviene mencionar que las reformas de 2013-2014 pusieron fin a dos instrumentos que contribuían a asegurar un mayor control de los partidos sobre la representación política: la obligación de que los candidatos fueran postulados por partidos políticos con registro y la prohibición de reelección consecutiva para diputados y senadores. Si bien la introducción de la figura de candidato independiente no provocó una proliferación de candidaturas -en parte por el carácter estricto de los requisitos de su registro-su existencia como vía de salida frente a tensiones externas tendrá el efecto de reducir la capacidad de imposición de disciplina de las dirigencias partidistas, como se verá en el caso de Acción Nacional. La introducción de la posibilidad de reelección consecutiva de diputados y senadores (si bien será efectiva a partir de 2021 en el primer caso y 2024 en el segundo) contribuye también a reducir el control de las dirigencias de lo que eran los tres grandes partidos sobre sus posibles candidatos.

En pocas palabras, el periodo 2012-2018 atestigua un proceso de erosión del sistema tripartita que presidió el proceso de cambio político mexicano desde la última década del siglo xx. La evolución de las preferencias electorales y la dificultad de restringir legalmente la dispersión de la repre-

${ }^{8}$ Alicia Hernández de Gante y Adrián Gimate-Welsh, "El debate legislativo en torno al umbral electoral en la reforma político electoral de 2013-2014”, Revista Mexicana de Ciencias Políticas y Sociales, 52, núm. 232, pp. $40-42$.

${ }^{9}$ Véase la contribución de Willibald Sonnleitner en este número. 
sentación terminaron por minar las bases de ese sistema à la Huntington. Pero también, como veremos a continuación, la situación interna de esos partidos contribuyó de manera importante a la transformación del sistema de partidos.

\section{B. LAS CRISIS PARTIDISTAS}

El modelo à la Huntington no suponía sólo la existencia de un sistema de partidos altamente institucionalizado, pues buscaba que sus pilares fueran formaciones políticas igualmente institucionalizadas. Si bien ese objetivo nunca se alcanzó plenamente, se puede afirmar que los tres principales partidos lograron, bien que mal, cada uno con su propio modelo y su peculiar combinación de procedimientos formales e informales, construir un entramado institucional que les permitiera administrar su vida interna y adquirir cierta estabilidad organizacional. Durante el periodo 2006-2012 esos modelos entran en crisis y muestran, en grados distintos, fragilidad y vulnerabilidad.

\section{El Partido Acción Nacional}

La derrota electoral de Acción Nacional en 2012, cuando su candidata presidencial, Josefina Vázquez Mota, terminó en un distante tercer lugar, dio inicio a un periodo de mucha turbulencia en la vida interna del partido (véase cuadro 2). Doce años en el poder no habían permitido resolver las tensiones generadas por su condición de "partido de gobierno", donde parecían oponerse de manera casi constante el aparato partidista y el equipo que rodeaba al presidente en turno, este último tratando de imponer sus colaboradores cercanos en la dirigencia de la organización. A pesar de tratarse de grupos distintos, esa nueva realidad marcó la vida de Acción Nacional tanto durante el sexenio de Vicente Fox como durante el de Felipe Calderón y siguió existiendo con el regreso 
a la oposición. ${ }^{10}$ Lo que en su momento había hecho del PAN “... el partido con el mayor nivel de apertura y democracia interna...", en palabras de Víctor Alarcón, es decir, la congruencia entre estatutos y prácticas, el debate programático interno y la competencia civilizada por los cargos de poder y las candidaturas, parecía pertenecer a otra época. ${ }^{11}$ Trataré la crisis de ese partido tomando en consideración tres dimensiones: las diferencias entre grupos internos, sus relaciones con otros partidos y su accidentado desempeño electoral.

\section{CuAdro 2}

Elecciones presidenciales 2000-2018

\begin{tabular}{|c|c|c|c|c|}
\hline Partido Político & $2000 *$ & $2006 * *$ & $2012 * * *$ & $2018 * * * *$ \\
\hline PRI & 13579718 & 9301441 & 19226784 & 9289853 \\
& $(31.11 \%)$ & $(22.23 \%)$ & $(38.21 \%)$ & $(16.4099 \%)$ \\
\hline \multirow{2}{*}{ PAN } & 15989636 & 15000284 & 12786647 & 12610120 \\
& $(42.52 \%)$ & $(35.89 \%)$ & $(25.41 \%)$ & $(22.2750 \%)$ \\
\hline \multirow{2}{*}{ PRD } & 6256780 & 14756350 & 15896999 & \\
& $(16.64 \%)$ & $(35.33 \%)$ & $(31.59 \%)$ & \\
\hline Morena & - & - & - & 30113483 \\
& & & & $(53.1936 \%)$ \\
\hline Otros***** & 955866 & 1530654 & 1150662 & 2961732 \\
& $(2.55 \%($ & $(3.67 \%)$ & $(2.29 \%)$ & $(5.2317 \%)$ \\
\hline
\end{tabular}

Fuente: elaboración propia con base en datos del Instituto Nacional Electoral.

${ }^{10}$ Es un argumento que desarrollé con más detalles en Jean-François Prud'homme, "El Partido Acción Nacional y el Partido de la Revolución Democrática después de las elecciones de 2012", Arturo Alvarado (coord.), Elecciones en México: cambios, permanencias y retos, México, El Colegio de México, 2016, pp. 113-121. De hecho, retomo alguna información plasmada en ese capítulo cuando hago referencia a los tres primeros años del sexenio 2012-2015.

${ }^{11}$ Víctor Alarcón Olguín, "Democracia interna y selección de candidatos presidenciales en México. De la simulación a la competencia", Flavia Freidenberg y Manuel Alcántara Sáez (ed.), Selección de candidatos, política partidista y rendimiento democrático, México, Universidad de Salamanca-Universidad Nacional Autónoma de México-Tribunal Electoral del Distrito Federal, 2009, p. 156. 
En los meses posteriores a las elecciones presidenciales del 1 de julio de 2012, el análisis de la derrota y, sobre todo, la reforma de los estatutos de Acción Nacional se volvieron temas de disputa en el seno del partido. Una primera propuesta emitida por el presidente Calderón de convocar una asamblea de refundación -antes del fin de su mandato- fue rechazada por 26 de los 32 presidentes estatales de Acción Nacional. Se creó entonces una Comisión de Evaluación y Mejora que tuvo por objeto elaborar una reforma de los estatutos de la organización con el sentido de reforzar las facultades del Comité Ejecutivo Nacional en cuanto a propuestas de candidaturas y de resolución de conflictos internos. Sin embargo, la asamblea prevista para marzo de 2013 fue suspendida un día después por falta de quorum sin que se discutieran las reformas. Lo único que se aprobó fue una resolución de Javier Corral a efecto de que las autoridades del partido fueran electas directamente por los militantes. No es hasta agosto de 2013 que se volvió a convocar a la asamblea para que, al fin, se aprobaran las reformas. Esas tensiones en torno a las reglas de funcionamiento interno, las fechas de convocatorias para elecciones internas y selección de candidatos, así como los métodos de su designación se volvieron constantes durante el sexenio. Veremos más adelante cómo esas situaciones se repitieron cuando fue momento de designar al sucesor de Gustavo Madero a la cabeza del partido, a los candidatos plurinominales para las elecciones legislativas de 2015 y, luego, al candidato presidencial para 2018. El partido, reconocido por la congruencia y eficacia de sus reglas y procedimientos para la administración de su vida interna, vivió momentos difíciles.

Esa crisis fue en gran parte el producto de la consolidación de grupos y facciones en el seno de la organización: el PAN era definitivamente un partido fragmentado. A la dinámica de oposición entre "los hombres del presidente" y los miembros del aparato se agregaban importantes desacuerdos entre las instancias regionales y el Comité Ejecutivo Nacional. La oposición entre poder ejecutivo y dirigencia partidista adquirió irónicamente, a finales del sexenio del presidente Cal- 
derón, visos similares a los que se habían dado al final del sexenio del presidente Fox. En 2010, Gustavo Madero ganó la presidencia del partido frente al calderonista Roberto Gil Zuarth; en 2012, Josefina Vázquez Mota venció al calderonista Ernesto Cordero para la candidatura presidencial de la misma manera que, en 2005, Felipe Calderón le ganó la candidatura al foxista Santiago Creel. Así, se definió un primer eje de conflicto entre el equipo de Madero y los calderonistas que dominaban la bancada de Acción Nacional en el senado. De ahí, los intentos de la dirigencia panista de controlar los grupos parlamentarios en la Cámara de Diputados y en el Senado. Ese eje se prolongó luego en torno a los reiterados intentos infructuosos de Margarita Zavala, esposa de Felipe Calderón, para ser candidata a diputada plurinominal, presidenta del partido y luego candidata presidencial.

El estilo de gestión de Gustavo Madero provocó también diferencias con el panismo de las regiones que reivindicaba una mayor participación de los miembros de la base en los procesos internos, tal como lo expresó en varias ocasiones el senador Javier Corral. Si bien hubo periodos de calma relativa al inicio de la gestión de Ricardo Anaya, quien sustituyó a Madero que se había ido a dirigir al grupo parlamentario de los diputados de Acción Nacional, los conflictos volvieron a aflorar al acercarse la elección presidencial de 2018.

La cuestión de las candidaturas tanto a cargos internos de la organización como a cargos de elección popular reavivó periódicamente las tensiones entre grupos y facciones. En 2010, Gustavo Madero había sido electo presidente del PAN por un escaso margen de siete votos (129 contra 122 para Roberto Gil). Como hemos visto, su mandato estuvo marcado por grandes dificultades de gobernanza interna. Su periodo llegaba a su fin en diciembre de 2013 sin que se hubieran definido ni las reglas de la competencia, ni la fecha de la contienda interna. Una primera reunión del Consejo Nacional para tal efecto abortó, mientras que tres presuntos candidatos al cargo (Josefina Vázquez Mota, Juan Manuel Oliva y Ernesto Cordero) solicitaban al presidente saliente $-\mathrm{y}$ candidato 
a la reelección- restituir la "institucionalidad" del partido. Finalmente, después de una campaña dura que desbordó ampliamente los límites de la organización y de la renuncia de la candidata Vázquez Mota, el binomio Madero-Anaya venció en la elección de mayo 2014 a la fórmula Cordero-Oliva con $57.4 \%$ de los votos. En septiembre de 2014, Gustavo Madero pidió licencia para competir para un cargo de diputado en las siguientes elecciones legislativas de 2015. En los hechos, las recriminaciones públicas entre grupos no habían cesado. Ricardo Anaya fue designado presidente interino. En enero de 2015, la Comisión Permanente Nacional de Acción Nacional, cercana al maderismo, elaboró una lista de candidatos plurinominales para las legislativas de junio con candidatos afines. Pero lo que más afectó la relación entre grupos fue el rechazo a la candidatura de Margarita Zavala: era el inicio del último capítulo de la lucha por las candidaturas. ${ }^{12}$

Después de ese rechazo, la esposa del expresidente Calderón expresó, primero, su deseo de ser candidata a la presidencia del partido teniendo en mente el relevo de Madero, que ocurriría después de las legislativas de 2015. Luego, en junio de 2015, anunció su voluntad de ser candidata presidencial por Acción Nacional en 2018. Durante todo ese periodo, alentada por encuestas de opinión favorables, mantuvo la presión sobre las autoridades del partido para ser una interlocutora relevante en la definición de la estrategia electoral y las reglas de selección del candidato presidencial hacia $2018 .{ }^{13}$ Sin embargo, ante la poca receptividad de las autoridades a sus demandas y la nula posibilidad de que prosperara su candidatura, anunció en octubre de 2017 su renuncia al PAN y su intención de postularse como candidata indepen-

12 “Desdeña PAN a Margarita Zavala”, Milenio, 12 de enero 2015, https:// www.milenio.com/politica/desdena-pan-a-margarita-zavala (consulta del 5 de agosto de 2019).

13 "Margarita Zavala destapa ambición presidencial para 2018", Excélsior, 14 de junio de 2015, https:/ / www.excelsior.com.mx/nacional/2015/ 06/14/1029450 (consulta del 5 de agosto de 2019). 
diente a la presidencia de la República. ${ }^{14}$ A su renuncia siguió el lento abandono de las filas del partido de varias personalidades asociadas al calderonismo.

Esa decisión marcó el inicio del fin de las tensiones internas generadas por el conflicto entre partidarios del expresidente y la corriente maderista. De cierta manera, la posibilidad de salida que ofrecía la nueva modalidad de "candidatura independiente", hecha posible con la reforma electoral de 2014, contribuía a reducir la tensión interna en el seno de la organización en una coyuntura de toma de decisiones estratégicas. De hecho, como veremos más adelante, la correlación de fuerzas interna había evolucionado en el seno de la organización desde la elección de Ricardo Anaya en sustitución de Gustavo Madero, en agosto de 2015. Esto obliga a hacer referencia a un elemento que adquirió mucho peso en la vida de Acción Nacional en el periodo que nos interesa: el manejo de la relación con el ámbito externo de la organización como activo en las relaciones de poder internas.

Dos episodios marcaron la estrategia externa del PAN durante el sexenio: la participación en la negociación del Pacto por México y la creación de coaliciones electorales con otros partidos, principalmente con el PRD.

En diciembre de 2012, se anunció la negociación y el acuerdo al cual habían llegado el gobierno del presidente Peña Nieto y las dirigencias del PAN y del PRD en torno a 95 propuestas de políticas públicas. El acuerdo conocido como Pacto por México tenía por objeto superar las dificultades inherentes a una situación de gobierno dividido y favorecer la colaboración legislativa en torno a una serie de reformas que se juzgaban esenciales en materia fiscal, energética, laboral, educativa y política, entre otras. El acuerdo desplazaba el eje de la negociación entre el poder ejecutivo y el poder legislativo hacia las dirigencias de los partidos de oposición.

14 "Margarita Zavala deja el PAN y culpa a Anaya", Sin Embargo, Ciudad de México, 6 de octubre de 2017, https://www.sinembargo.mx/06-102017/3323534 (consulta del 5 de agosto de 2019). 
Fue una magnífica oportunidad de consolidación de la frágil presidencia de Gustavo Madero, uno de sus más ardientes defensores en Acción Nacional, propulsándolo en el centro de la vida política nacional. En sus propias palabras, $80 \%$ de la agenda de las reformas que integraban el Pacto se debieron a propuestas de su partido. A la vez, fue una fuente más de conflicto con la bancada de los senadores panistas integrada principalmente por allegados al expresidente Calderón, que al final terminaron siendo descartados de su coordinación. ${ }^{15}$ Lo que cabe subrayar aquí es, otra vez, el uso de recursos externos en la elaboración de estrategias orientadas hacia la vida interna de la organización.

El otro aspecto de la política externa del partido que adquirió importancia durante el sexenio fue la política de coaliciones electorales. No era la primera vez que el PAN forjaba alianza con otros partidos para derrotar al PRI: en el pasado, esa estrategia le había permitido conseguir victorias electorales, sobre todo en el ámbito local. Sin embargo, esta vez, la estrategia iba a pesar más en la definición de situaciones internas del partido.

El 17 de agosto de 2015, Ricardo Anaya, quien había sido brevemente presidente interino del PAN durante una licencia de algunos meses de Gustavo Madero, fue oficialmente electo presidente de Acción Nacional con $81 \%$ de los votos. Su contrincante, Javier Corral, no logró hacer realidad su convocatoria a una "rebelión" en contra del grupo que había "secuestrado" el partido. ${ }^{16}$ La estrategia de armar coaliciones electorales con vista a las elecciones federales de 2018 dominará el periodo de la gestión de Anaya.

Doce elecciones al cargo de gobernador estaban previstas para junio de 2016. Desde el 9 de septiembre de 2015, se iniciaron negociaciones con el PRD para algunas de éstas. En

${ }^{15}$ Prud'homme, "El Partido Acción Nacional...", art. cit., pp. 115-116.

16 "Elección en el Pan: Ricardo Anaya gana y será el nuevo dirigente nacional", Animal Político, 16 de agosto de 2015, https:/ /www.animalpolitico.com/2015/08/inicia-la-eleccion-de-dirigente-nacional-del-pan/ (consulta del 5 de agosto de 2019). 
febrero de 2016, Anaya y el presidente del PRD, Agustín Basave, anunciaron que iban a competir en coalición en cuatro de las elecciones (Oaxaca, Zacatecas, Veracruz y Durango), y luego Quintana Roo se agregó a lista. ${ }^{17}$ La estrategia funcionó: el 5 de junio de 2016, Acción Nacional ganó siete de las doce gubernaturas que estaban en juego, tres de ellas en coalición. De hecho, el PRI perdió cuatro estados en los cuales nunca antes había habido alternancia en el poder. ${ }^{18}$

Ese episodio electoral fue interpretado como una victoria de Ricardo Anaya y de su estrategia. En ese contexto, otros panistas interesados en la candidatura presidencial de 2018 empezaron a manifestar sus intenciones de manera más abierta: ya se mencionó el caso de Margarita Zavala, pero también el gobernador de Puebla, Rafael Moreno Valle, inició actividades proselitistas. En reiteradas ocasiones, voces en el partido exhortaban a Ricardo Anaya a no usar su cargo de presidente para promover su candidatura presidencial. De hecho, las negociaciones para crear una coalición electoral anti PRI seguían en la agenda: en noviembre de 2016, los gobernadores electos de Acción Nacional se pronuncian a favor de una alianza con otras fuerzas políticas. ${ }^{19}$ Las elecciones a gobernador en tres estados (Coahuila, México y Nayarit) en junio de 2017 mostraron un saldo negativo para Acción Nacional, pero consolidaron la estrategia de alianza, pues la única victoria se consiguió en Nayarit en coalición con el PRD.

${ }^{17}$ Luis Pablo Beauregard, "El PAN y PRD apuestan por aliarse para vencer al PRI en las elecciones”, El Pais, 4 de febrero de 2016, https:/ / el pais.com/internacional/2016/02/04/mexico/1454609543_900363.html (consulta del 5 de agosto de 2019).

18 Tania L. Montalvo, "2016, el año de la derrota histórica del PRI en elecciones estatales", Animal Político, 7 de junio de 2016, https://www.animalpolitico.com/2016/06/2016-el-ano-de-la-derrota-historica-del-pri-enelecciones-estatales/ (consulta del 5 de agosto 2019).

19 "Gobernadores del PAN piden alianza para Edomex", Milenio, $21 \mathrm{de}$ diciembre de 2016, https:/ / www.milenio.com/politica/gobernadores-delpan-piden-alianza-para-edomex (consulta del 5 de agosto de 2019”. 
A finales de junio de 2017, la Comisión Permanente aprobó la creación de un frente opositor. En septiembre del mismo año, el PAN, el PRD y Movimiento Ciudadano (MC) confirmaron su intención de contender en las elecciones de 2018 apoyando una candidatura única en un Frente Ciudadano por México. ${ }^{20}$ En octubre, como ya lo vimos, Margarita Zavala abandonó el partido. El 20 de noviembre se decidió por consenso de las tres fuerzas políticas coaligadas que Ricardo Anaya iba a ser el candidato de la coalición. El 9 de diciembre renunció a la dirigencia del partido y el 10 se concretó su precandidatura a la presidencia por la coalición Por México al Frente, que se haría oficial posteriormente, en febrero de 2018. ${ }^{21} \mathrm{Al}$ final, la construcción de la candidatura de Ricardo Anaya se dio en dos planos paralelos: en el seno del partido y con los futuros aliados de la coalición. Cada uno de esos campos sirvió para fortalecer su posición en el otro y para seguir cerrando espacios a sus contrincantes y, en especial, a la corriente afín a Felipe Calderón.

Ahora, la fortaleza de las organizaciones partidistas no se define solamente por su capacidad de administrar los conflictos internos y de manejar las relaciones estratégicas con sus competidores. Los resultados electorales suelen pesar mucho en su vitalidad. Durante el sexenio 2012-2018, el PAN tuvo resultados electorales volátiles. En las elecciones presidenciales de 2012, su candidata, Josefina Vázquez Mota, terminó en un lejano tercer lugar con $25.4 \%$ de los votos, víctima de un voto de sanción a dos sexenios de gobiernos de Acción Nacional, de las disputas internas entre facciones que

${ }^{20}$ Héctor Gutiérrez y Magali Juárez, "PAN, PRD y MC formalizan ante el INE alianza electoral", El Financiero, 5 de septiembre de 2017, https:/ /www. elfinanciero.com.mx/nacional/pan-prd-y-mc-presentan-el-frente-ciudadano-por-mexico (consulta del 5 de agosto de 2019).

${ }^{21}$ Suzzete Alcántara, "Ricardo Anaya toma protesta como candidato de la coalición Por México al Frente”, El Universal, 18 de febrero de 2018, https://www.eluniversal.com.mx/elecciones-2018/ricardo-anaya-tomaprotesta-como-candidato-de-la-coalicion-por-mexico-al-frente (consulta del 5 de agosto de 2019). 
ya documentamos y de una campaña que nunca logró despegar. Sin embargo, ese resultado que en su momento parecía preocupante, representaba todavía tres puntos más del porcentaje de votos que conseguiría Ricardo Anaya como candidato presidencial en 2018 (22.2\%) (véase cuadro 2). Esa tendencia a la baja en el desempeño electoral de Acción Nacional se puede observar de manera constante en los resultados obtenidos en las elecciones para diputados: en efecto, de 2006 a 2018, cada tres años se registra un retroceso de tres a cuatro puntos en el porcentaje de votos obtenidos, de tal manera que Acción Nacional pasa de tener 33.4\% de respaldo en las elecciones legislativas de 2006 a sólo $17.9 \%$ en las de 2018 (véase cuadro 1 ).

Ahora bien, a pesar de esas tendencias continuas a la baja en el apoyo de los electores, el campo de la competencia electoral no trajo sólo malas noticias para el PAN. Hemos visto cómo algunos resultados positivos en elecciones estatales contribuyeron a alentar la estrategia de coaliciones que se desarrolló con insistencia en la segunda mitad del sexenio. En efecto, en 2016, el PAN ganó sorpresivamente siete de las doce contiendas electorales a gobernadores, logrando desplazar al PRI en tres estados donde nunca se había dado la alternancia en el poder. Ese resultado se explica en gran parte por la capacidad que mostró Acción Nacional de captar, en ese momento, el voto de los numerosos ciudadanos insatisfechos con el gobierno del presidente Peña Nieto y de usar su sólida estructura organizativa para canalizar esa insatisfacción en los estados donde hubo elecciones. Esas victorias mostraron ser efímeras e ilusorias, como pudo apreciarse en las elecciones a gobernadores de 2017, en las que Acción Nacional ganó una de tres contiendas, y en las elecciones de 2018, en las que sólo ganó tres de nueve. En el fondo, como se observó en esas últimas elecciones, el PAN ya no era el vehículo idóneo de expresión del voto de sanción de los ciudadanos. La tendencia en las preferencias electorales marcaba más bien un constante retroceso en la capacidad de movilizar votos. 
En síntesis, el periodo 2012-2018 significó para Acción Nacional grandes dificultades en la administración de su gobernanza interna, el recurso más frecuente a estrategias externas para hacer frente a esas dificultades y un retroceso permanente, aunque con una pequeña burbuja de esperanza en 2016, en su capacidad de movilizar votos.

\section{El Partido de la Revolución Democrática}

La derrota electoral del candidato presidencial de la coalición Movimiento Progresista, Andrés Manuel López Obrador, en 2012, a pesar de mostrar un saldo positivo que le permitió remontar de un tercer lugar en las encuestas a un segundo lugar, seis puntos detrás del vencedor, incrementar la representación del PRD en la Cámara de Diputados de 71 a 104 diputados y consolidar de manera impresionante la hegemonía de su partido en el Distrito Federal (63.5\% de los votos para su candidato a jefe de gobierno), marcó el inicio de la debacle. En efecto, el 9 de septiembre, Andrés Manuel López Obrador anunció su renuncia al PRD y su intención de transformar su Movimiento de Regeneración Nacional en partido político. Ese desenlace no sorprendió: fue el resultado de tensiones que nacieron en las protestas poselectorales de 2006, se fueron acentuando a lo largo del sexenio del presidente Calderón y conocieron una breve calma en la elección presidencial de 2012. ${ }^{22}$

La vida interna del Partido de la Revolución Democrática siempre fue agitada. Se trata de un partido de masas en el cual coexistieron permanentemente facciones formales conocidas como corrientes, con un liderazgo personal de corte carismático y donde la institucionalización era el producto de una curiosa mezcla de reglas y procedimientos formales e in-

22 Analicé los antecedentes que explican la separación entre López Obrador y el PRD en Prud'homme, "El Partido Acción Nacional...", art. cit., pp. 121-129. 
formales. En general, los conflictos internos se administraban mediante la intervención del líder carismático y de negociaciones cupulares informales en el seno de la elite partidista. ${ }^{23}$ Analizaré la crisis del PRD a partir de tres dimensiones: la relación entre los distintos grupos y facciones, los vínculos con otros partidos y la acelerada pérdida de apoyo en el electorado.

La cuestión de la gobernanza en el seno de esa formación política ha sido frecuentemente problemática. Más de una elección interna para la designación de las autoridades del partido ha dado lugar a impugnaciones y, a veces, a su anulación. En marzo de 2008, la elección a la presidencia de la organización, en la cual ganó Jesús Ortega frente a Alejandro Encinas, dio lugar a una impugnación ante el Tribunal Electoral del Poder Judicial de la Federación y, luego, a negociaciones entre las cúpulas de las distintas corrientes para avalar sus resultados. Dicha elección enfrentó no sólo a estas corrientes, esencialmente Nueva Izquierda e Izquierda Democrática, con posiciones propias en cuanto a sus actividades como oposición, sino que estaba en juego también el apoyo que aportaban (o no) a la estrategia de desconocimiento del gobierno del presidente Calderón, que dirigía su excandidato presidencial, Andrés Manuel López Obrador. Mientras tanto, este último recorría el país para fortalecer la organización de su "gobierno legítimo" y tomaba distancia con el PRD, llegando a solicitar licencia del partido y, luego, a anunciar la creación del Movimiento de Regeneración Nacional (Morena) en marzo de 2011: se expresaba de manera más acentuada una progresiva separación entre liderazgo carismático y corrientes organizadas. El mal desempeño del partido en las legislativas de 2009 y la cercanía de las elecciones de 2012 dieron lugar a una gran operación de reconciliación en apoyo a la candidatura presidencial de López Obrador, recurriendo una vez más a la negociación cupular y, sobre todo, a la ampliación de los límites organizacionales del PRD para

${ }^{23}$ Prud'homme, "El sistema de partidos", art. cit., pp. 149-151. 
incluir, en una vasta coalición electoral llamada Frente Progresista, a la gran familia ideológica de los partidos de izquierda. Cuando después de la derrota de 2012, Andrés Manuel López Obrador quiso mantener, una vez más, acciones de protesta denunciando supuestas irregularidades electorales, la dirigencia del PRD optó por no apoyarlo. Es en ese contexto que ocurrió el anuncio de su renuncia al partido. ${ }^{24}$

Inicialmente, la salida de López Obrador fue recibida públicamente con cordialidad y respeto por la dirigencia partidista y gran parte de la militancia: Jesús Zambrano, presidente del partido, saludó la posición tomada por el "camarada” López Obrador y le expresó sus mejores deseos. El buen resultado conseguido en las elecciones legislativas de 2012, la actitud expectante de la mayoría de las corrientes del partido ante la popularidad real que tendría Morena en las preferencias ciudadanas y, probablemente, la esperanza de mantener un lugar preponderante en una familia ideológica de la izquierda dialogante, contribuyeron a explicar esta actitud serena. La corriente de Nueva Izquierda mantenía el control sobre el aparato del partido y, desde una posición subordinada, la otra gran corriente del PRD, Izquierda Democrática Nacional (IDN), parecía apostar a la institucionalidad partidista. Ese frágil equilibrio se mantuvo cuidando los procedimientos de consulta y elecciones internas, de tal manera que se pudieran evitar las movilizaciones masivas de las bases de las distintas corrientes, que una entidad externa (el Instituto Nacional Electoral) se encargara de la organización de esos procesos y que se mantuvieran los canales de negociación entre cúpulas. Sin embargo, detrás de esa aparente situación de control del conflicto, seguía dándose una guerra de posiciones entre corrientes, desacuerdos en cuanto a la actitud a adoptar como partido de oposición frente al gobierno en turno y dificultades para hacer frente a acontecimientos imprevistos en el entorno más amplio del

${ }^{24}$ Prud'homme, "El Partido Acción Nacional", art. cit., 2016, pp. $130-131$. 
sistema político. En el fondo, los motivos que habían sido una fuente constante de tensiones en el sexenio anterior seguían muy presentes.

En cuanto a los vínculos con otras fuerzas políticas, la dirigencia del PRD asumió al principio del sexenio el compromiso de desarrollar un "trabajo legislativo constructivo" y, en palabras de su presidente, promovió la iniciativa de colaboración entre las dirigencias partidistas y el poder ejecutivo conocida como Pacto por México. Inicialmente, a pesar de las críticas de la corriente IDN, la participación en el Pacto fue aprobada por el $80 \%$ de los participantes en el xiv Congreso Nacional del partido. Un poco como sucedía al mismo tiempo en Acción Nacional, la participación en el Pacto permitía reforzar la presencia y la influencia del presidente en turno del partido, Jesús Zambrano, en la arena política nacional. Esa influencia se pudo apreciar en las reformas fiscal y política, esa última permitiendo la adopción de un nuevo estatuto para el Distrito Federal. Sin embargo, como pasaba en el PAN, tanto el mecanismo de concertación ideado en el Pacto, como el contenido de ciertas reformas que incluía, provocaron resistencia en las bancadas parlamentarias del partido y en las corrientes ajenas a Nueva Izquierda.

A partir de noviembre de 2013, la discusión de la reforma al sector energético marcó el límite de la participación del PRD en el Pacto y fue el inicio del lento desvanecimiento de ese mecanismo. Dada la importancia del tema de la propiedad nacional de los medios de explotación de los recursos energéticos para la izquierda, el PRD no podía sino oponerse a la reforma y convocar a movilizaciones en contra de ésta. A la vez, su capacidad de movilización en contra de la iniciativa de ley era muy limitada dado que había apoyado firmemente las demás reformas incluidas en el Pacto: su dirigencia estaba atrapada entre la colaboración constructiva y la oposición frontal al gobierno. Es más, fracasó en su intento de unirse a Morena y otras fuerzas de izquierda en las protestas contra la reforma del sector energético, mostrando 
los nuevos límites de su capacidad de acción en el universo más amplio de la familia ideológica de izquierda.

Aun así, en las elecciones internas que se realizaron en septiembre de 2014 para designar a los nuevos integrantes del Consejo Nacional, que a su vez iban a elegir al nuevo presidente del partido, la coalición dominante que se articulaba en torno a la corriente Nueva Izquierda logró casi el $70 \%$ de los votos de los militantes registrados, mientras que Izquierda Democrática Nacional obtuvo sólo 17\%. El 4 de octubre fue electo presidente Carlos Navarrete de la corriente Nueva Izquierda sin que hubiera impugnaciones. Una vez más, el PRD parecía haber solucionado sus problemas de gobernanza interna.

No obstante, el 26 de septiembre de 2014, 43 estudiantes de una escuela rural fueron secuestrados y, probablemente, asesinados en la ciudad de Iguala, Guerrero, dando lugar al tristemente conocido caso de Ayotzinapa. El alcalde de Iguala, quien luego fue apresado por ese caso, y el gobernador del estado eran del PRD y estaban asociados a Nueva Izquierda. Durante los días posteriores a los hechos, la nueva dirigencia de la organización adoptó una posición ambigua, que buscaba evitar la renuncia del gobernador Aguirre en medio de protestas internas, incluyendo la de Cuauhtémoc Cárdenas, que pidió la renuncia de la nueva dirigencia del partido y terminó abandonándolo. En pocos días, el saldo aparentemente positivo de una contienda interna bien llevada se transformaba en una crisis moral y ética en medio de duras críticas.

La designación de candidatos a diputados para las elecciones legislativas de 2015 fue otra prueba para la organización. En febrero, Marcelo Ebrard renunció al partido seguido por tres diputados federales: algunos para pasarse a Morena, otros manteniéndose en la expectativa. Muchos, como Alejandro Encinas, acusaban que el PRD era una organización sin rumbo, desfigurada y corrompida por un pequeño grupo que se había adueñado de él. ${ }^{25}$ En las elecciones legislativas del 7 de

25 Shaila Rosagel, "El PRD cumple 26 años sin 30 de sus líderes más importantes, sin festejo y en silencio”, Sin Embargo, 5 de mayo de 2015, 
junio de 2015, el Revolucionario Democrático se enfrentó por primera vez a Morena en una contienda formal. Si bien el PRD se mantuvo como principal fuerza de izquierda a nivel nacional con $11.4 \%$ de los votos, había obtenido apenas 2.5 puntos más que Morena. Sobre todo, perdió su bastión de la Ciudad de México ante su nuevo rival, ganando sólo 5 distritos uninominales federales contra 16 para Morena, 6 delegaciones contra 5 y 19 curules contra 22 para su adversario en la Asamblea Legislativa de la Ciudad de México. Ante tal saldo, el 8 de agosto, Carlos Navarrete anunció su intención de dejar la presidencia del partido. En principio, la renovación de la dirigencia se iba a dar en la tercera semana de septiembre, pero no fue hasta noviembre que la renuncia se hizo efectiva. ${ }^{26}$ Mientras tanto, se eligió a Agustín Basave como nuevo dirigente del PRD después del desistimiento de dos de sus posibles contendientes, Armando Ríos Peter y Zoé Robledo, que abandonaron la contienda aduciendo que era una simulación, ya que se había perfilado un aspirante en particular. ${ }^{27}$ Ambos dejaron el partido meses después.

En los hechos, durante los últimos meses de 2014 y el primer semestre de 2015, el PRD entró de manera más llana a una dinámica de descomposición sostenida. La gobernanza interna ya no era tanto un problema de relaciones entre distintos grupos y corrientes, aun si éstas seguían activas y tendían a multiplicarse con el surgimiento de nuevos temas de desacuerdo, sino más bien de retención de personalidades políticas históricas de la organización que, una por una, y de manera sostenida, manifestaban o su desinterés o su

https:/ / www.sinembargo.mx/05-05-2015/1334261 (consulta del 5 de agosto de 2019).

26 “Agustín Basave es el nuevo dirigente nacional del PRD”, Animal Político, 7 de noviembre de 2015, https:/ / www.animalpolitico.com/2015/11/ agustin-basave-es-el-nuevo-dirigente-nacional-del-prd/ (consulta del 5 de agosto de 2019).

27 Angélica Mercado, “Zoé Robledo se baja de contienda por PRD”, Milenio, 5 de noviembre de 2015, https:/ / www.milenio.com/politica/zoerobledo-se-baja-de-contienda-por-prd (consulta del 5 de agosto 2019). 
voluntad de dejar la organización. Y si el partido conservaba el gobierno de la Ciudad de México y de algunos estados como Morelos, Michoacán y Tabasco, su capacidad de movilización de votos por sí mismo estaba muy disminuida. Con la renuncia de Navarrete se inició un periodo de inestabilidad en la dirigencia del partido con una sucesión de dirigentes efímeros: las corrientes dominantes en la organización gobernaban el vacío.

En cuanto a los vínculos con otras fuerzas políticas, la llegada de Agustín Basave a la cabeza del PRD coincidió con la aplicación de una estrategia alternativa de movilización de votos. Como lo hemos visto en el apartado anterior, el PRD empezó negociaciones para competir en coalición con Acción Nacional en varios estados donde se iban a celebrar elecciones a gobernador en 2016: primero fue el caso de Durango y Zacatecas y luego se agregaron Oaxaca, Veracruz y Quintana Roo. La estrategia de formar coaliciones con el PAN para "poner freno a la restauración autoritaria del PRI" suscitó tensiones en el seno de los órganos de dirección del PRD y provocó una disputa entre las corrientes aliadas de Izquierda Democrática y Alternativa Democrática Nacional. Muchos integrantes del Comité Ejecutivo Nacional insistían en el carácter excepcional de esas estrategias. Basave amenazó con renunciar si no se aprobaba la formación de coaliciones con el PAN en algunas contiendas estatales. ${ }^{28}$ Claramente, el tema de la unión de fuerzas con un partido asociado a la derecha se volvió otra fuente de tensión en la organización y motivo de desafección de un mayor número de militantes.

De hecho, las elecciones estatales del 5 de junio de 2016, concurrentes con una consulta para integrar la Asamblea Constituyente de la Ciudad de México, no fueron un gran éxito para el PRD. Si bien la coalición con Acción Nacional ganó

${ }^{28}$ Shaila Rosagel, "Tribus del PRD pelean por poder, no por ideología: analistas; 15 grupos guerrean por liderazgo", Sin Embargo, 21 de enero de 2016, https://www.sinembargo.mx/21-01-2016/1602799 (consulta del 5 de agosto 2019). 
en Veracruz, Quintana Roo y Durango, esas victorias fueron interpretadas como victorias de Acción Nacional: en Quintana Roo, el candidato victorioso no era afiliado al PRD mientras que en los otros estados los candidatos eran panistas. En cuanto a la consulta para integrar la Asamblea Constituyente en la Ciudad de México, se confirmó el retroceso del partido frente a Morena: sus candidatos obtuvieron $31.5 \%$ de los votos frente a $36.2 \%$ para los candidatos de Morena. ${ }^{29}$ El 18 de junio, Basave renunció a la presidencia del partido, no debido a los resultados electorales sino, en sus palabras, por la dificultad de arbitrar las tensiones entre corrientes y, particularmente, roces con la corriente Nueva Izquierda. ${ }^{30}$ El 16 de julio resultó electa Alejandra Barrales como presidenta del PRD, personalidad cercana a Miguel Ángel Mancera, jefe de gobierno de la Ciudad de México. ${ }^{31}$

A partir de ese momento, la política de alianza con el PAN primero y, luego, con Movimiento Ciudadano, pasó a dominar la vida interna de la organización en un contexto de definición de las candidaturas presidenciales de 2018. Varios gobernadores perredistas, Graco Ramírez de Morelos, el recién electo Silvano Aureoles de Michoacán y, desde luego, Miguel Ángel Mancera, de la Ciudad de México, dejaban ver su interés en ser postulados. ${ }^{32}$

${ }^{29}$ David Marcial Pérez, "Morena vuelve a golpear en Ciudad de México pero no tumba al PRD”, El País, 6 de junio de 2016, https:/ /www.sinem bargo.mx/21-01-2016/1602799 (consulta del 5 de agosto de 2019).

${ }^{30}$ Isabel González, "Agustín Basave renuncia a la dirigencia del PRD”, Excélsior, 18 de junio de 2016, https://www.excelsior.com.mx/nacional/ 2016/06/18/1099610 (consulta del 5 de agosto de 2019).

31 "Alejandra Barrales, nueva presidenta del PRD”, El Economista, 16 de julio de 2016, https://www.eleconomista.com.mx/politica/Alejandra-Ba rrales-nueva-presidenta-del-PRD-20160716-0009.html (consulta del 5 de agosto de 2019).

32 "Silvano Aureoles y Graco Ramírez alzan la mano y van por la candidatura presidencial del PRD”, Animal Político, 2 de marzo de 2017, https:// www.animalpolitico.com/2017/03/silvano-graco-candidatura-prd / (consul ta del 5 de agosto de 2019). 
Ahora bien, la opción de regresar a la estrategia de ampliación de las negociaciones al conjunto de la "familia de izquierda" como en el pasado (o como se creyó que sería posible en los primeros años del sexenio) quedaba anulada. Así se observó en las discusiones sobre la posibilidad de apoyar a la candidata de Morena en las elecciones a gobernador de junio de 2017 en el Estado de México. Morena era claramente un rival y el PRD no tenía el capital político suficiente para atraer a otras fuerzas de izquierda.

Desde la perspectiva de las elecciones presidenciales de 2018, la solución consistió en buscar la formación de un frente ciudadano que buscara ocupar un centro ampliado para ubicarse entre Morena y el PRI. No obstante, esa estrategia seguía provocando resistencias en el PRD: por ejemplo, en diciembre de 2016, Miguel Barbosa creó un frente denominado Militantes de Izquierda, que reunía a tres corrientes del partido y cuyo propósito era apoyar a un solo candidato de izquierda en 2018 y frenar la descomposición ideológica del partido. ${ }^{33}$ A finales de marzo de 2017, 11 de los 20 senadores del PRD decidieron dejar de trabajar con ese grupo parlamentario y actuar como ala legislativa de Morena en el Senado. ${ }^{34}$ En mayo, Dolores Padierna, llamó a la militancia del partido a rebelarse contra la decisión del Comité Ejecutivo Nacional de aliarse con el PAN en 2018. ${ }^{35}$ Ella renunciaría al partido en septiembre de 2017 y apoyaría la candidatura de Andrés Manuel López Obrador, lo mismo

33 Susana Guzmán y Héctor Gutiérrez, "Surge nueva corriente en el PRD: Militantes de izquierda”, El Financiero, 14 de diciembre de 2016, https://www.elfinanciero.com.mx/nacional/surge-nueva-corriente-en-elprd-militantes-de-izquierda (consulta del 5 de agosto de 2019).

${ }^{34}$ Leticia Robles de la Rosa, "El PRD se desmorona en el Senado; abandonan 12 la bancada”, Excélsior, 29 de marzo de 2017, https://www.excel sior.com.mx/nacional/2017/03/29/1154690 (consulta del 5 de agosto 2019).

35 Susana Guzmán, "Padierna llama a la rebelión en el PRD por posible alianza con AN", El Financiero, 27 de junio de 2017, https:/ /www.excelsior. com.mx/nacional/2017/03/29/1154690 (consulta del 5 de agosto 2019). 
que el anuncio de un mes antes de personalidades del PRD, como Pablo Gómez, Leonel Godoy y Carlos Sotelo. La sangría provocada por la perspectiva de alianza con Acción Nacional continuaba. En septiembre de 2017, en el noveno Consejo Nacional del PRD, se aprobó la creación de un Frente Democrático Nacional, antesala para que en noviembre se aprobara una coalición electoral con el PAN y MC con vistas a las elecciones de $2018 .{ }^{36} \mathrm{Y}$ si bien a inicios de diciembre la dirigencia del PRD manifestó su apoyo a Miguel Mancera como precandidato presidencial del partido, cuando el 12 de diciembre la coalición Por México al Frente se registró ante el Instituto Nacional Electoral, ya se sabía que su candidato presidencial iba a ser Ricardo Anaya, del PAN. A cambio, Alejandra Barrales iba a ser candidata de la coalición para la jefatura de gobierno de la Ciudad de México y Miguel Mancera iba a encabezar la lista de senadores plurinominales: quedaba claro que el PRD era un socio menor en esa alianza electoral. Mientras tanto, a lo largo del primer semestre de 2018, más personalidades históricas del partido anunciaron su apoyo al candidato de la coalición Juntos Haremos Historia.

En el transcurso del sexenio 2012-2018, la aparición de una organización exitosa surgida de una escisión en la organización y encabezada por un líder carismático, las luchas internas entre grupos y facciones y la política de alianzas con otras fuerzas políticas que no eran aliados naturales, aceleraron la debacle del PRD. Es algo que puede apreciarse en la estrepitosa y siempre más veloz caída del partido en las preferencias electorales.

Ya comentamos que el saldo de las elecciones federales de 2012 había sido relativamente positivo para el PRD. Su candidato presidencial había terminado en segundo lugar, seis puntos detrás del vencedor tras haber iniciado la campaña en

36 “Consejo del PRD aprueba ir en coalición con PAN y Movimiento Ciudadano en 2018”, Animal Político, 19 de noviembre de 2017, https:/ / www.animalpolitico.com/2017/11/prd-coalicion-elecciones-2018/ (consulta del 5 de agosto de 2019). 
un lejano tercer lugar; su bancada en la Cámara de Diputados se había incrementado con 33 diputados más y su candidato a la jefatura de gobierno de la Ciudad de México había arrasado en los comicios locales una mayoría de 63\%. Cuando Morena obtuvo su registro como partido político durante el verano de 2014, las encuestas sobre preferencias electorales le atribuían solamente $7 \%$ en las preferencias de los encuestados.

La situación empezó a deteriorarse con las elecciones legislativas federales de 2015. Ya en ese momento, empezaban a darse migraciones de su militancia y personal político hacia Morena. Si bien sus candidatos a diputaciones federales obtuvieron el $11.4 \%$ de los votos y fueron electos 56 diputados, ese resultado significaba un retroceso de 8 puntos con respecto a la elección anterior y una pérdida de 48 escaños (cuadro 1). El partido mantenía una ventaja de apenas 2.5 puntos sobre Morena. El indicador más importante de esa elección fue la derrota en la batalla por conservar el bastión de izquierda que es la Ciudad de México. Ya mencionamos que la ganó Morena, con 16 diputados federales contra 5 para el PRD, 22 asambleístas contra 19 y 6 delegaciones frente a 5 para Morena (había ganado 14 en 2012). Esa tendencia se volvió a confirmar en 2016 con las elecciones para la integración de la Asamblea Constituyente de la Ciudad de México, cuando el PRD quedó en segundo lugar, cinco puntos detrás de Morena.

Pero el descalabro electoral se dio en las elecciones federales de 2018. El PRD obtuvo sólo el $5 \%$ de los votos en las elecciones para diputados federales, lo que redujo su bancada en la Cámara de Diputados a 21 representantes. En el Senado logró la elección de solo 8 senadores contra 22 en 2012, con una pérdida de más de 13 puntos. Esa representación se vio luego mermada por las migraciones de legisladores a otras formaciones políticas, sobre todo hacia Morena: en julio de 2019, la bancada del PRD en la Cámara de Diputados tenía 11 integrantes y la del Senado, sólo 5. En la Ciudad de México, Alejandra Barrales, de la coalición Por México al 
Frente consiguió sólo el $31 \%$ de los votos frente al $47 \%$ de Claudia Sheinbaum, candidata vencedora por Juntos Haremos Historia. El tamaño de la derrota del PRD y la sustitución de hegemonía partidista en la ciudad capital se evidenció también en la pobre capacidad de retención de las alcaldías (antes delegaciones), donde el PRD conservó apenas cuatro frente a las once ganadas por Morena, y en los resultados de la nueva composición de la Asamblea Legislativa de la CDMX, con apenas 4 asambleístas perredistas y 37 de Morena. Esos resultados son muy significativos dado que, durante todo el sexenio, el PRD había apostado hacer de la Ciudad de México un modelo de gobierno de izquierda progresista y moderno. Parece que ese proyecto no logró ser atractivo para el electorado de la capital.

En síntesis, el sexenio de 2012-2018 atestiguó la casi desaparición de una fuerza política que había sido uno de los tres pilares del sistema de partidos de la transición mexicana. La situación parecía confirmar una hipótesis formulada por Kay Lawson en su estudio sobre los partidos que fracasan: el surgimiento de escisiones exitosas en partidos establecidos acarrea grandes riesgos en cuanto a su supervivencia, sobre todo cuando logran ocupar sus funciones de intermediación. ${ }^{37}$

\section{El Partido Revolucionario Institucional}

El caso del PRI difiere del PAN y del PRD. A diferencia de esos dos partidos, no fue víctima de una crisis de gobernanza interna, sino del voto de castigo a su gobierno. La victoria elec-

37 Kay Lawson, "When Linkages Fails", Kay Lawson y Peter Merkl (eds.), When Parties Fail: Emerging Alternative Organizations, Princeton, University Press, 1988, p. 30. En realidad, Lawson formula una hipótesis que no logra comprobar, a partir de los casos que estudia, a efecto de que organizaciones alternativas logran sobrevivir cuando asumen exitosamente las funciones de intermediación, anteriormente desarrolladas por partidos deficientes. El caso del PRD y Morena parece confirmar la hipótesis. 
toral de Enrique Peña Nieto en 2012 fue la culminación de un proceso largo, pero exitoso, de reconstrucción de un liderazgo nacional. Esa reconstrucción se dio desde la periferia de la organización, apoyándose en los nuevos hombres fuertes del sistema político mexicano, los gobernadores. A partir de 2008, Enrique Peña Nieto logró erigirse como la figura articuladora de una coalición de gobernadores que se impuso frente a las autoridades más tradicionales del partido (dirigentes de la organización y líderes parlamentarios). En efecto, desde la derrota electoral del 2000, con la pérdida de la titularidad del poder ejecutivo, el PRI había perdido también la figura política que tradicionalmente arbitraba los conflictos entre sus grupos y facciones, la del presidente de la República. Se tardó 12 años en recuperar ambas: la titularidad del ejecutivo y la figura política que aseguraba la gobernanza interna. ${ }^{38}$ Sin embargo, durante todo ese periodo, el partido había logrado conservar un sólido caudal de votos y una envidiable presencia en gran parte del territorio nacional, como lo atestiguaban tanto sus resultados en elecciones legislativas como en las de gobernadores. Es más, en las elecciones federales intermedias de 2009 y presidenciales de 2012 fue el principal beneficiario del voto de protesta contra el gobierno de Felipe Calderón.

Con un cómodo apoyo del $38.2 \%$ del electorado, una bancada en la cámara de diputados ligeramente más pequeña que en la legislatura anterior, pero sustantiva, y una ganancia de casi 20 escaños en el senado, el presidente Peña Nieto dio inicio a su mandato en una posición de fuerza aun si, al igual que sus antecesores, tenía que hacer frente a una situación de gobierno dividido. Esa posición de fuerza pudo apreciarse con el anuncio, el 2 de diciembre de 2012, un día después de la toma de posesión del nuevo gobierno, de un amplio acuer-

${ }^{38}$ Para un excelente análisis del proceso de fragmentación y reconfiguración de las élites estatales y nacional del PRI después del 2000, Rogelio Hernández, "El refugio del PRI durante la alternancia panista", Foro Internacional 55, núm. 219, 2015, pp. 45-82. 
do programático y legislativo que abarcaba 95 compromisos específicos y una serie de grandes reformas legislativas en los campos de la educación, las telecomunicaciones, la fiscalidad, la política y vida electoral y la producción de energía.

La peculiaridad del Pacto por México residía en que, como lo hemos visto en apartados anteriores, era el producto de una negociación y un acuerdo entre la presidencia de la República y las dirigencias de los tres grandes partidos políticos, sobre todo de la oposición. Parecía aportar una solución a la situación de gobierno dividido que prevalecía desde 1997, en la que se dificultaba la cooperación legislativa en torno a reformas importantes, como las incluidas en el acuerdo. De hecho, ese mecanismo de cooperación funcionó de manera muy eficaz hasta noviembre de 2013, cuando el PRD empezó a marcar sus distancias por el contenido de la reforma energética, aun si siguió cooperando después con otras reformas legislativas incluidas en el Pacto como, por ejemplo, la reforma político-electoral. Si bien, desde un punto de vista formal, ese gran acuerdo fue un éxito de negociación, hemos visto cómo desató tensiones y desacuerdos importantes en el seno de los partidos de oposición participantes. A lo largo de 2014, ese mecanismo de concertación se fue desvaneciendo poco a poco.

Desde una perspectiva de cohesión interna del partido gobernante, el presidente Peña Nieto logró en un primer momento restablecer cierta unidad en la clase política del PRI. Había llegado al poder apoyado por una amplia coalición de gobernadores, pero logró integrar un gabinete que reflejaba bien la diversidad de los grupos de poder en su partido, una "elite renovada" en palabras de Rogelio Hernández. ${ }^{39}$ De hecho, como pudo apreciarse en el contenido de algunas reformas legislativas, por una coincidencia de intereses del poder ejecutivo y de los partidos de oposición, se dio un proceso de recentralización del poder. Por ejemplo, el Instituto Federal

39 Rogelio Hernández y Will G. Pansters, "La democracia en México y el regreso del PRI”, Foro Internacional 52, 210, 2012. 
Electoral se transformó en Instituto Nacional Electoral y el Instituto Federal de Acceso a la Información en Instituto Nacional de Acceso a la Información: en ambos casos, más allá del cambio de nombre, se dotaba a las autoridades de estos órganos autónomos federales de facultades para acotar, vigilar y, en su caso, intervenir en campos de actividad donde los gobernadores habían gozado de una amplia libertad de acción.

Sin embargo, detrás de esos aparentes éxitos en materia de gobernanza, había una sorprendente vulnerabilidad que se hizo evidente en el otoño de 2014. La manera en que el gobierno reaccionó a los trágicos hechos de Iguala en septiembre de 2014 -conocidos como el caso Ayotzinapa por el nombre de la escuela normal rural de donde provenían las víctimas-y, luego, a una situación de conflicto de interés que involucró a la esposa del presidente, publicitada en noviembre del mismo año y referida en la opinión pública como el caso de la Casa Blanca, mostró tanto su fragilidad como la de su proyecto político. Por más que el equipo de gobierno estuviera cohesionado detrás de un proyecto bien definido y muy racional, no lograba convencer a la ciudadanía.

El problema no era sólo de imagen y comunicación, sino que tenía raíces más profundas asociadas a la falta de confianza política. En los primeros meses del nuevo gobierno, el PRI contaba con 20 gobernadores. ${ }^{40}$ Como ya se ha mencionado, la candidatura del presidente había sido apoyada por una coalición amplia de mandatarios estatales priistas donde él aparecía como el líder de los nuevos hombres fuertes del sistema político. Como exgobernador del Estado de México, su figura pública estaba estrechamente vinculada a la de esos personajes. Durante el sexenio, el ocaso de la imagen de gobernadores todopoderosos fabricada en años anteriores no fue sólo el resultado de acciones ideadas desde el centro y los partidos de oposición para restringir su margen de acción, fue también producto de su asociación con la realiza-

${ }^{40} \mathrm{Ibid} ., 785$. 
ción de actos delictivos frecuentemente ligados al tema de la corrupción. En efecto, de 2010 a 2018, 16 gobernadores fueron investigados por presuntos actos delictivos, y de éstos, seis terminaron en la cárcel. Es cierto que no todos fueron del PRI y no todos fueron condenados, pero la gran mayoría provenía de ese partido y eran contemporáneos del presidente. ${ }^{41}$ Eso contribuyó ampliamente a la omnipresencia del espectro de la corrupción en la vida pública mexicana durante los seis años del gobierno de Enrique Peña Nieto, imagen que también se apoyaba en la experiencia cotidiana de los mexicanos: en 2017, la Encuesta Nacional de Calidad e Impacto Gubernamental aplicada por el Inegi mostraba un incremento de $16.2 \%$ en la tasa de prevalencia de corrupción, es decir, de ciudadanos que reportaron haber sido víctimas de actos de corrupción.

Otro tema de preocupación para la población fue el de la violencia. El inicio de la gestión del nuevo gobierno pareció marcar una voluntad de cambio en la estrategia de lucha contra la delincuencia, como lo indicó la intervención del gobierno federal en el estado de Michoacán. De hecho, durante los dos primeros años el número de homicidios dolosos disminuyó, al pasar de 20568 en 2012 a 15649 en 2014. Sin embargo, en los años restantes, se elevó de nuevo para alcanzar la cifra de 157006 para el sexenio, con un incremento notable y constante en los últimos años. Esa cifra rebasa el número alcanzado en cualquier sexenio anterior (véase cuadro 3 y gráfica 1). No es de sorprender que los ciudadanos identificaran como principales problemas del país, la inseguridad y la violencia, el desempleo, la carestía y la corrupción. Si bien la preocupación por la inseguridad fue creciendo a lo largo del sexenio (58\% en 2015 vis a vis $64.5 \%$ en 2018), el malestar contra la corrupción se mantuvo estable entre $28 \%$ y $30 \%$, lo que, de todas maneras, es una tasa significativa (véase cuadro 4).

${ }^{41}$ Fundar, Fue un mal año. No, menos como seis, México, Fundar, 2018, p. 84 . 
FI LX-2 Partidos y Sistema de Partidos en las Elecciones de 2018431

\section{Cuadro 3 \\ Homicidios dolosos}

\begin{tabular}{|c|c|}
\hline Año & Total \\
\hline 2012 & 20568 \\
\hline 2013 & 18106 \\
\hline 2014 & 15649 \\
\hline 2015 & 17889 \\
\hline 2016 & 22567 \\
\hline 2017 & 28866 \\
\hline 2018 & 33341 \\
\hline
\end{tabular}

\section{GRÁFICA 1}

Homicidios dolosos, 2012-2018

$\multimap$ Total

42500

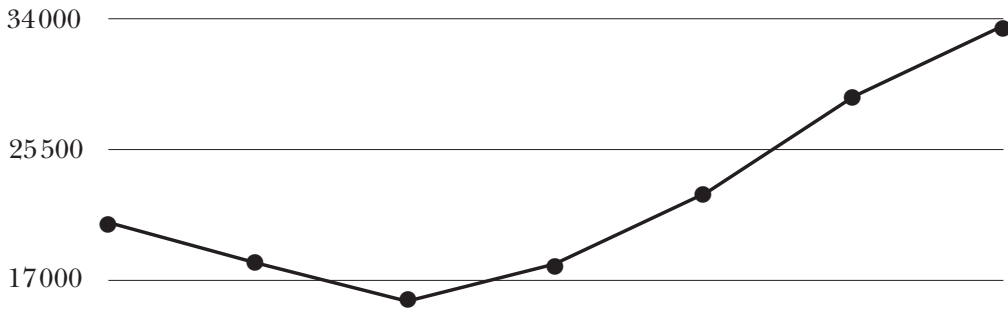

8500

0

$\begin{array}{lllllll}2012 & 2013 & 2014 & 2015 & 2016 & 2017 & 2018\end{array}$

Fuente: elaboración propia con información del Secretariado Ejecutivo del Sistema Nacional de Seguridad Pública. 
Cuadro 4

Principales preocupaciones de los mexicanos

\begin{tabular}{|l|c|c|c|c|}
\hline \multicolumn{1}{|c|}{ Tema } & 2015 & 2016 & 2017 & 2018 \\
\hline Inseguridad & $58 \%$ & $59.1 \%$ & $61.1 \%$ & $64.5 \%$ \\
\hline Desempleo & $44.1 \%$ & $40.8 \%$ & $36.3 \%$ & $36.3 \%$ \\
\hline Pobreza & $31.1 \%$ & $31.9 \%$ & $27.9 \%$ & $27.8 \%$ \\
\hline Aumento de precios & $33.2 \%$ & $30.7 \%$ & $36.5 \%$ & $36.3 \%$ \\
\hline Salud & $28.6 \%$ & $30.1 \%$ & $28.8 \%$ & $25.3 \%$ \\
\hline Corrupción & $28.5 \%$ & $28.2 \%$ & $29.1 \%$ & $29.2 \%$ \\
\hline Educación & $22.7 \%$ & $21.7 \%$ & $21 \%$ & $19.6 \%$ \\
\hline Impunidad & $17.7 \%$ & $20.3 \%$ & $21.5 \%$ & $21.4 \%$ \\
\hline Narcotráfico & $17.2 \%$ & $16.1 \%$ & $16.7 \%$ & $18.9 \%$ \\
\hline Escasez de agua & $13.2 \%$ & $14.3 \%$ & $14.6 \%$ & $15.2 \%$ \\
\hline
\end{tabular}

Fuente: Encuesta Nacional de Victimización y Percepción sobre Seguridad Pública (Envipe) 2016, 2017, 2018.

La percepción de esos problemas se tradujo en tasas bajas y, sobre todo, descendientes, de aprobación ciudadana en cuanto al desempeño del gobierno. Como puede observarse en el cuadro 5, en diciembre de 2012, el presidente tenía una tasa de aprobación del $57 \%$ contra $30 \%$ de desaprobación. Rápidamente, en diciembre de 2013, la proporción de los ciudadanos que aprobaban la gestión del gobierno era ya menor a los que la desaprobaban ( $45 \%$ frente a $47 \%$ ). En noviembre de 2018 , la tasa de aprobación ya había caído a $22 \%$ frente a $73 \%$ de desaprobación. Dos hechos llaman la atención: aun en momentos en que el gobierno parecía tener éxito en la formulación y aplicación de sus políticas públicas, la tasa de desaprobación era superior a la tasa de aprobación; luego, en comparación con sexenios anteriores, la valoración del presidente era consistentemente más negativa $^{42}$ (véase gráfica 2 ).

42 Véase Oraculus “Aprobación presidencial”, disponible en https:// oraculus.mx/aprobacion-presidencial/, consultado el 5 de agosto 2019. 


\section{CUADro 5}

Aprobación y desaprobación de Enrique Peña Nieto

\begin{tabular}{|c|c|c|}
\hline & Aprobación & Desaprobación \\
\hline 2012 & 57 & 30 \\
\hline 2013 & 45 & 47 \\
\hline 2014 & 38 & 55 \\
\hline 2015 & 36 & 58 \\
\hline 2017 & 17 & 79 \\
\hline 2018 & 22 & 73 \\
\hline
\end{tabular}

\section{GRÁFICA 2}

Aprobación y desaprobación de Enrique Peña Nieto

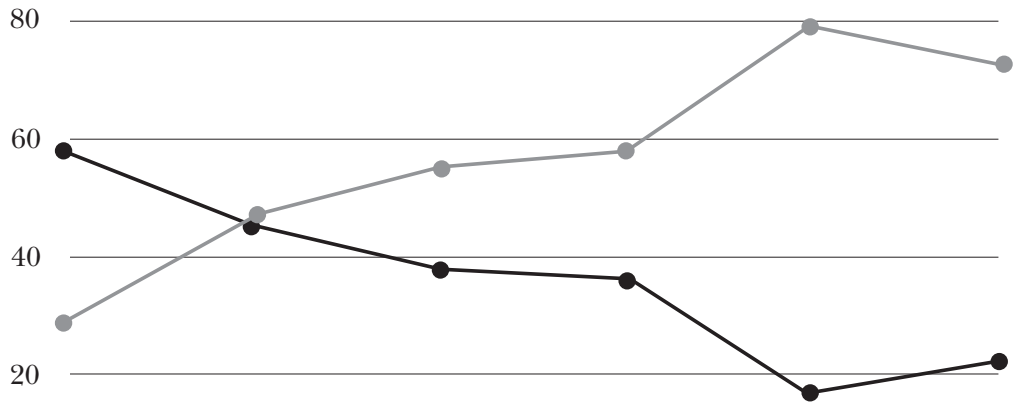

0

2012

2013

2014

2015

2017

2012

Fuente: elaboración propia con información del Poll of Polls de Oraculus. 
Aun así, esas tendencias en la opinión pública no se reflejaron inmediatamente en los resultados electorales. A pesar de las derrotas sucesivas en las elecciones presidenciales de 2000 y 2006 , el PRI mantuvo su "refugio" en las instancias locales, consolidando su presencia en el territorio nacional y afinando "sus habilidades como maquinaria partidista". ${ }^{43} \mathrm{Ya}$ mencionamos el importante número de gubernaturas en manos de ese partido en 2012: de hecho, en 2018, con menos gobernadores electos, seguía siendo el partido con el mayor número de gobernadores electos. En las elecciones legislativas de 2009 obtuvo 237 diputaciones cosechando el voto de castigo contra el presidente panista, más todavía de los que obtendrá Morena en su aplastante victoria de 2018 (véase cuadro 1). Yaunque existía una percepción negativa del desempeño gubernamental en las elecciones intermedias de 2015, el PRI perdió apenas nueve escaños con casi cien diputados (98, para ser preciso) más que el partido con la segunda bancada en la Cámara, Acción Nacional (114 diputados).

Es solamente en las elecciones de junio de 2016, para renovar 12 gubernaturas, que se prendieron las primeras señales de alarma. En efecto, el PRI sólo logró la victoria en cinco de ellas. ${ }^{44} \mathrm{Y}$ si bien pudo recuperar el estado de Oaxaca, perdió en cuatro estados en los cuales nunca se había dado la alternancia: Durango, Quintana Roo, Veracruz y Tamaulipas. ${ }^{45}$ El PRI se quedaba con 15 gobiernos estatales, es decir, por primera vez en su historia, con menos de la mitad. Entre las razones que se mencionaron para explicar la derro-

${ }^{43}$ Rogelio Hernández, art. cit., 2015, 53.

44 "El PRI reconoce su derrota electoral, mientras el PAN destaca sus victorias históricas", Animal Político, 6 de junio de 2016, https://www.ani malpolitico.com/2016/06/lideres-del-pri-pan-y-prd-presumen-sus-venta jas-electorales-en-la-jornada-del-5-de-junio/ (consulta del 5 de agosto de 2019).

${ }^{45}$ Nayeli Roldán, "El PRI regresa a gobernar Oaxaca: Alejandro Murat es puntero en los resultados", Animal Político, 6 de junio de 2016, https:/ / www.animalpolitico.com/2016/06/el-pri-regresa-a-gobernar-oaxaca-ale jandro-murat-es-puntero-en-los-resultados/ (consulta del 5 de agosto 2019). 
ta, estaban las siguientes: la traición de militantes, el desgaste de los gobernadores, las reformas estructurales, entre otras. ${ }^{46}$ El problema residía no sólo en la dimensión aritmética de los resultados, también en su significado simbólico. La organización de las elecciones había estado en manos del nuevo presidente del PRI, Manlio Fabio Beltrones, conocido como miembro de la élite tradicional del partido, cercano al aparato y afamado organizador político. El 20 de junio, éste renunció a la dirigencia, responsabilizándose de la derrota. ${ }^{47}$ Hay otro mito que se vio afectado: el de la fuerza de la formidable maquinaria electoral del partido que tenía presencia en el conjunto de la geografía nacional. La capa protectora del "refugio" tradicional priista se estaba fisurando.

Hubo tres elecciones para renovar el poder ejecutivo en los estados en 2017. El PRI perdió Nayarit, pero conservó el poder en Coahuila y en el Estado de México. No obstante, sus victorias en ambos estados fueron muy apretadas. En Coahuila, el candidato del PRI, en coalición con otros partidos, Miguel Riquelme, obtuvo apenas 2.5 puntos más que su rival del PAN, Guillermo Anaya, apoyado por otra coalición ( $38.9 \%$ frente a $36.4 \%$ ). Los resultados fueron impugnados sin éxito por todos los demás candidatos. En el Estado de México, bastión del PRI y del grupo político del presidente Peña Nieto, la victoria de Alfredo del Mazo fue igualmente apretada: éste obtuvo $33.5 \%$ de los votos vis a vis el $30.8 \%$ de la candidata de Morena, Delfina Gómez. ${ }^{48}$ En esta elección,

${ }^{46}$ Leticia Robles de la Rosa, "El PRI analiza causas de las derrotas; investiga posible traición”, Excélsior, 9 de junio de 2016, https://www.excel sior.com.mx/nacional/2016/06/09/1097697 (consulta del 5 de agosto de 2019).

47 "Manlio Fabio Beltrones renuncia a dirigencia del PRI", Milenio, 20 de junio de 2016, https://www.milenio.com/politica/manlio-fabio-beltro nes-renuncia-dirigencia-pri (consulta del 5 de agosto de 2019).

${ }^{48}$ Leticia Robles de la Rosa, "PRI logra 2.65 millones de votos; le sigue Morena; Edomex, nicho electoral del tricolor", Excélsior, 6 de junio de 2017, https://www.excelsior.com.mx/nacional/2017/06/06/1167998 (consulta del 5 de agosto de 2019). 
el dato más preocupante para el PRI fue que su candidato había conseguido $35 \%$ de votos menos que su antecesor y compañero de partido, Eruviel Ávila. Además, esas victorias pírricas volvían a poner en el centro del debate político nacional la cuestión de la equidad en las condiciones de competencia y, en particular, la del financiamiento de las campañas.

Esos resultados ya dejaban presagiar la hecatombe electoral de 2018. Como puede apreciarse en las cuadros 1 y 2, el candidato presidencial del PRI, José Antonio Meade, terminó en un distante tercer lugar con apenas $16.4 \%$ de los votos, es decir casi 22 puntos menos que el resultado obtenido por Peña Nieto en 2012. En las elecciones para diputados, el PRI alcanzó también el tercer lugar con un porcentaje similar al de la elección presidencial, registrando una pérdida de 158 escaños. Algo similar sucedió en los comicios para senadores, donde la bancada pasó de 52 a 14. El PRI perdió también las nueve elecciones a gobernadores que se estaban disputando, quedándose con 12 gobernadores, muchos de ellos con nuevas legislaturas controladas por Morena. En pocas palabras, el tan celebrado aparato electoral del PRI fue aplastado en las elecciones de 2018.

En cuanto a la relación entre grupos y facciones en el seno del partido durante el sexenio, fueron mucho más fluidas que las que prevalecieron en los otros dos grandes partidos tradicionales. En ese sentido, sí se recuperó la figura tradicional del presidente como timón de la gobernanza interna de ese partido, aun si se dieron tensiones a nivel local en coyunturas particulares. Desde luego, el momento de selección del candidato presidencial generó leves tensiones, pero al final prevaleció el candidato del presidente y el método tradicional de unción del elegido. En su momento fueron mencionados Miguel Ángel Osorio Chong, Manlio Fabio Beltrones, Ivonne Ortega, Eruviel Ávila, cada quien representando grupos más cercanos a la organización partidista. Al final prevaleció José Antonio Meade en calidad de candidato "ciudadano" del PRI y, por más que se haya instalado una Comisión Política Permanente que diseñó procedimien- 
tos internos de selección del candidato, al final hubo un solo precandidato, a la usanza tradicional. ${ }^{49}$ Meade era parte del círculo cercano al presidente Peña Nieto, lo mismo que el presidente del PRI, Enrique Ochoa, y el jefe de campaña, Aurelio Nuño. En mayo de 2018, ante las pocas perspectivas del candidato señaladas por las encuestas de opinión, Ochoa fue relevado por René Juárez, un político con una trayectoria más tradicional: el relevo fue interpretado como un intento de mantener cohesionadas las bases políticas del partido. ${ }^{50}$ En ese momento ya se hablaba de "brazos caídos" en la campaña y de discretos apoyos a la del candidato de Morena.

En suma, el sexenio empezó relativamente bien para el gobierno de Peña Nieto, aun si el presidente nunca logró gozar de alta popularidad en la sociedad. El viraje sobrevino en el otoño de 2014 (con los casos de Ayotzinapa y de la Casa Blanca) que mostró la fragilidad del gobierno y su dificultad de comunicarse con la población. La desaprobación creciente de los ciudadanos tardó hasta 2016 para expresarse en las urnas, mientras que seguía creciendo la tasa de desaprobación del gobierno. Los temas de la inseguridad, la economía y la corrupción alimentaron esa insatisfacción y fue el voto de castigo el que provocó el espectacular derrumbe electoral del PRI. La consecuencia más directa de la derrota electoral es el desmantelamiento de un sistema de ejercicio del poder que se había construido a lo largo de casi noventa años. En 2018, el PRI perdió la mayoría de sus múltiples anclas institucionales y organizativas; su regreso parece haber sido su canto del cisne.

49 Ariadna García, "Instala PRI Comisión para procesos internos al 2018”, El Universal, 22 de noviembre de 2017, https://www.eluniversal. com.mx/nacion/politica/instala-pri-comision-para-procesos-internosal-2018 (consulta del 5 de agosto de 2019).

50 "Meade dice que él decidió quitar a Ochoa la dirigencia del PRI y que hará más ajustes en su campaña”, Animal Político, 3 de mayo de 2018, https://www.animalpolitico.com/2018/05/meade-ochoa-cambio-cam pana/ (consulta del 5 de agosto de 2019). 


\section{Morena}

Desde luego, el derrumbe del sistema de partidos que presidió la transición mexicana no fue solamente el resultado de los problemas de gobernanza interna o de rechazo de la gestión de las tres grandes organizaciones políticas mexicanas. No puede explicarse sin el surgimiento de una fuerza que se presentó como una alternativa viable a los partidos establecidos: Morena. ${ }^{51}$

Como hemos visto en el apartado sobre el PRD, Morena nace, en gran parte, de un lento proceso de escisión de ese partido grande de la izquierda mexicana. Las tensiones internas que afloraron a lo largo del sexenio 2006-2012 entre la corriente de Izquierda Democrática, que controlaba la burocracia partidista, y Andrés Manuel López Obrador fueron insuperables después de las elecciones federales de 2012: el desacuerdo en torno a la estrategia a adoptar frente al nuevo gobierno seguía siendo profundo. La calificación de la contienda electoral que permitió la victoria del PRI y de su candidato, así como, un poco después, la participación en el Pacto por México, terminaron de conducir a una ruptura anunciada, en la que estaban en juego la cooperación limitada o la confrontación con el nuevo gobierno. Aun así, hasta las elecciones legislativas de 2015, todavía estaba presente la idea de la posibilidad de coexistencia de las dos organizaciones en una coalición de la gran familia ideológica de izquierda.

Sin embargo, una vez que Morena se registró como partido político, quedó claro que se trataba de una organización

${ }^{51}$ Por cuestiones de falta de espacio, no voy a desarrollar a fondo el proceso de surgimiento y consolidación de Morena. Me limitaré a exponer los elementos que explican su éxito. Esta sección se apoya esencialmente en Jean-François Prud'homme, art. cit., 2016, para los tres primeros años del periodo estudiado y, sobre todo, para el periodo posterior, en la excelente tesis de maestría de Fernando Luna, "Morena: la formación de un partido político y sus primeros rasgos organizativos, tesis de Maestría en Ciencia Política, México, Centro de Estudios Internacionales, El Colegio de México, 2018, pp. 86-120. 
política que competía exitosamente con el PRD por el respaldo de los electores de izquierda. De entrada, Morena ganó las batallas electorales en los bastiones de la izquierda, como lo mostraron los resultados de las elecciones locales y federales en la Ciudad de México en 2015, de las elecciones para la integración de la Asamblea Constituyente de la misma entidad en 2016 y también el sólido segundo lugar en las elecciones para gobernador en el Estado de México, en 2017, de la candidata de Morena, Delfina Gómez, apenas dos puntos detrás del vencedor del PRI y con una inmensa ventaja sobre el candidato del PRD. En pocas palabras, poco a poco, Morena se estaba consolidando como la alternativa de izquierda, es decir, como el producto de una escisión que desplazaba su organización de origen.

¿Era Morena sólo una escisión del PRD? Sí, en la medida en que esa red de políticos y organizaciones se articulaba en torno a la figura carismática de López Obrador que, después de todo, había pasado los veinte últimos años de su vida política en el seno del PRD, como presidente del partido, jefe de gobierno del Distrito Federal y dos veces candidato derrotado a la presidencia de la República, de una coalición de izquierda. A la fecha, el fundador del movimiento goza de un gran poder personal en la organización, de la cual es sin lugar a dudas el elemento aglutinador. Y también porque los personajes de peso en el seno de la organización eran -y son- en esencia políticos profesionales que ocuparon cargos de importancia en el PRD antes de la escisión, basta con revisar las listas de dirigentes de la nueva organización política o de representantes en cargos de elección popular para constatarlo. Y no, en la medida en que una proporción importante, probablemente mayoritaria, de la militancia morenista se adhirió al movimiento a raíz de las actividades proselitistas llevadas por el líder del partido desde 2006. No, porque un segmento importante de los electores de Morena y de López Obrador nunca había votado por el PRD en elecciones anteriores. Es posible constatar cómo, con excepción de la Circunscripción 2, que corresponde a grosso modo a los estados del noreste del 
país, el candidato de la coalición Juntos Haremos Historia terminó en primer lugar con un impresionante caudal de votos. Y aún en el caso de esa circunscripción, logró duplicar su respaldo electoral con respecto a 2012 (véase cuadro 6).

Cuadro 6

Resultados electorales de AMLO por circunscripción, 2012 y 2018

\begin{tabular}{|c|c|c|c|c|c|}
\hline Circunscripción & 1 & 2 & 3 & 4 & 5 \\
\hline 2012 & $2356455(3)$ & $1974821(3)$ & $3518658(2)$ & $4662065(1)$ & $3336828(2)$ \\
\hline 2018 & $5360233(1)$ & $4391505(2)$ & $6986092(1)$ & $6963053(1)$ & $6412600(1)$ \\
\hline
\end{tabular}

Fuente: elaboración propia con base en los datos del IFE/INE.

No, también porque la coalición Juntos Haremos Historia, que se construyó para respaldar la candidatura de López Obrador, era mucho más amplia que el segmento de militantes escindidos del PRD. Dicha coalición incluyó partidos de izquierda, como el Partido del Trabajo, y de derecha evangelista, como el Partido Encuentro Social, así como partidos locales y expolíticos del Partido Acción Nacional y del Partido Revolucionario Institucional. Al inicio de la campaña, se anunció la formación de un futuro gabinete que incluía a empresarios, académicos, magistrados y expolíticos, sin vinculación orgánica con el nuevo partido.

Finalmente, se adhirieron a la coalición movimientos sociales que agrupaban a organizaciones campesinas y obreras disidentes, no necesariamente progresistas. Esa alianza heterogénea sirvió de base para suplir la deficiencia inicial de presencia territorial de Morena y conquistar territorios electorales que habían sido tradicionalmente ajenos a la izquierda (cuadro 4). En palabras de Fernando Luna: "Esto hizo posible que Andrés Manuel López Obrador construyera una imagen como un representante fiel del 'pueblo', en tanto identidad colectiva, lo suficientemente importante en térmi- 
nos discursivos y a la vez ambiguo, para que cupieran todo tipo de perfiles, incluso los que poco antes fueron parte de la "mafia del poder". 52

Y así, Andrés Manuel López Obrador ganó las elecciones que un respaldo del $53 \%$ de los votantes, mayoría nunca vista desde la consolidación de un sistema electoral competitivo en México. Morena y sus aliados obtuvieron $43 \%$ de los votos para integrar la Cámara de Diputados y, poco a poco, con el flujo de migraciones provenientes principalmente del PRD, logró hacerse de la mayoría de los escaños en la cámara baja. Conquistó también la mayoría de los congresos estatales y ha ganado un número importante de elecciones para gobernador desde 2018 (seis si incluimos el estado de Morelos). En pocas palabras, cuatro años después de obtener su registro como partido político, Morena pasó a ocupar una posición dominante en un sistema de partidos mexicano totalmente reconfigurado.

\section{LAS PREFERENCIAS ELECTORALES}

Desde luego, la transformación del sistema de partidos no es solamente el resultado de la crisis interna de algunos partidos establecidos, de la insatisfacción con el partido en el poder ni tampoco del surgimiento de una organización política alternativa exitosa. Es, sobre todo, el resultado de un cambio profundo en las preferencias electorales.

Hemos visto que detrás del aparente control oligopólico de la representación política ejercido por los tres grandes partidos subsistían, por sí mismas, pequeñas formaciones políticas y que el número real de partidos fue creciendo de manera sostenida hasta alcanzar 5.6 en 2015. Es decir que, poco a poco, se creó un espacio para la existencia de otras organizaciones partidistas que tenían clientelas propias o que funcionaban con válvulas de escape para el voto de protesta. De

${ }^{52}$ Ibid, p. 120. 
la misma manera, a nivel local, estatal y también federal, los partidos tradicionales practicaban complejas políticas de alianza para dar acomodo a intereses políticos locales y estatales peculiares, o para conseguir apoyos electorales marginales que permitían ganar contiendas apretadas. En pocas palabras, detrás del dominio de los grandes partidos se escondía un mundo de representación de intereses más complejo.

Hemos visto al inicio de este artículo que, todavía en 2012, los tres grandes partidos establecidos recibían más de $80 \%$ de los votos en elecciones legislativas. En 2015, esa cifra había bajado a $64 \%$ y en 2018 a 39\%. En 2012, las bancadas de esos partidos -adversarios y competidores, desde luego- sumaban 430 diputados; en 2018, como resultado de las elecciones, sumaban apenas 147 diputados. Las trayectorias individuales de cada uno de esos partidos eran todavía más elocuentes. El PRD pasó de tener el 19\% de los votos en 2012 a sólo $5 \%$ en 2018; es decir, un resultado aceptable para un partido político marginal. Luego, ese $5 \%$ se haría minúsculo en términos de representación efectiva a raíz de un impresionante proceso de trashumancia de sus diputados hacia otras bancadas, particularmente la de Morena. Es un partido en vía de extinción. El PRD vio reducido su respaldo en elecciones legislativas a la mitad, pasando de $33.6 \%$ en 2012 a apenas $16.5 \%$ en 2018, una caída especialmente fuerte de 2015 a 2018: en efecto, perdió 148 escaños para quedarse con 45. Sobre todo, como ya lo indicamos, se quedó sin las anclas de su sistema de poder territorial que le permitía alimentar amplias redes clientelares y articular complejas configuraciones de intereses locales.

En el caso de Acción Nacional las pérdidas no fueron tan abruptas, pero sí constantes, entre tres o cuatro puntos porcentuales de una elección legislativa a la siguiente. Sigue siendo la segunda fuerza política del país con un número reducido, pero apreciable, de diputados (véase cuadro 1). En síntesis, las elecciones de 2018 significaron, en distintos grados, una impresionante derrota para los partidos que ocuparon un lugar central en el proceso de cambio político mexicano. En 
pocas palabras, el resultado del voto cambió la constelación de los partidos que contaban en el sistema político mexicano.

Llama la atención también el rápido ascenso de Morena. Obtuvo su registro como partido constituido y reconocido por la autoridad electoral en 2014 y terminó en cuarto lugar en las elecciones legislativas de 2015, con casi el $9 \%$ de la votación y 35 diputados. Tres años después, sus candidatos registrados bajo la bandera de Morena -algunos se registraron como candidatos de otros partidos como el PES, por ejemplo- consiguieron un $37 \%$ de respaldo en las elecciones para diputados: pasaron a integrar inicialmente una bancada de 191 diputados destinada a ir creciendo en función de reacomodos y migraciones interpartidistas.

Ahora bien, es importante mencionar también el hecho de que su candidato a la presidencia de la República obtuvo $53 \%$ de los votos con una ventaja de 31 puntos sobre su más cercano contendiente. Se ha subrayado con frecuencia que es el mejor resultado obtenido por un candidato presidencial desde 1982, fecha en que el nivel de competitividad del sistema de partidos no era muy elevado, para decir poco. Dos cosas llaman la atención: el diferencial de votos obtenidos por Andrés Manuel López Obrador en comparación no sólo con Morena, sino con el total de partidos integrantes de la coalición Juntos Haremos Historia (16 puntos en el primer caso y 10 en el segundo), y la conquista de territorios anteriormente ajenos al voto de izquierda. Para decirlo en breve, el apoyo electoral a la candidatura de López Obrador logró rebasar los límites territoriales, organizacionales y de lealtades partidistas existentes. Sin lugar a duda, el respaldo que le dieron los electores fue un factor fundamental en el trastrocamiento del sistema de representación política en México y en la gestación de otro diferente. 


\section{Conclusión}

Desde una perspectiva formal, retomando la clasificación de Sartori, puede hablarse del paso de un sistema multipartidista moderado, constituido por tres partidos principales y un número creciente de partidos secundarios, a un sistema de partido dominante. Para retomar los términos de Peter Mair, entre 2012 y 2018, se dio un cambio de categoría de sistema de partidos en México. Sin embargo, el tema es más complejo y aún es temprano para definir el nuevo sistema de partidos mexicano.

Desde la sola perspectiva de los resultados electorales, Morena queda en situación de dominación. El PRD está a punto de desaparecer; de hecho, el socio menor de la coalición Por México al Frente, Movimiento Ciudadano, tiene una representación tres veces superior a la del PRD en la Cámara de Diputados (27 diputados). El PRI está en una situación delicada no sólo por la magnitud de su derrota sino por el resquebrajamiento del sistema de poder que le permitía mantener una formidable maquinaria electoral a lo largo del territorio nacional. Por el momento, Acción Nacional, con una representación disminuida, se mantiene como un partido de oposición muy distante en cuanto al apoyo electoral de la mayoría gubernamental.

Más allá del factor numérico, el resultado de la elección de 2018 terminó de poner fin a una manera de concebir los partidos políticos y el mismo sistema de partidos. Ya mencioné que, al filo de las múltiples reformas electorales que permitieron la democratización del país, se creó una red protectora en torno al acceso a la representación política y a la canalización de las ambiciones e intereses a través de partidos bien establecidos. Es más, tales partidos se ubicaban idealmente en un abanico de posiciones programáticas que cubrían la derecha, el centro y la izquierda. Sus dirigencias tenían, bien que mal, los instrumentos para regular sus vidas internas y controlar las opciones de salida. Eran los encargados protegidos de la intermediación política para retomar el concepto 
de "linkage" desarrollado por Kay Lawson y Peter Merkl, antes mencionado. Desde luego, nunca se dio esa capacidad de control total del acceso a la representación política, pero sí había los instrumentos para pretender lograrlo o, por lo menos, permitir la existencia de una situación de virtual control oligopólico.

El proceso de cambio ya estaba en curso al inicio del periodo 2012-2018. Hemos visto que el número de partidos que cuentan estaba ya en ascenso y que las pequeñas formaciones políticas lograban mantenerse por sí solas o por la ejecución de hábiles estrategias de alianza. La legislación electoral adoptada a partir de 2012 introdujo la figura de las candidaturas independientes y, luego, en 2014, se aprobó la reelección consecutiva de los legisladores, minando así la capacidad de control de las dirigencias partidistas de los tres partidos establecidos: en distintos momentos, los tres grandes partidos tuvieron dificultades para administrar la gobernanza de sus respectivos aparatos. Sin embargo, es el surgimiento de una organización supletoria, Morena, lo que permitió la movilización y captación de votos en torno al proyecto del candidato presidencial Andrés Manuel López Obrador. Llama la atención la velocidad con la cual esa alternativa logró transformarse en una opción de poder mayoritaria.

En este contexto, cabe preguntarse, ¿por qué es muy temprano para hablar de un sistema de partido dominante? Morena sigue siendo una incógnita. Es un partido político recién creado -oficialmente, tiene cinco años de existencia- cuyas características institucionales no están claramente definidas. La organización se articula en torno a la figura carismática de su fundador, que ejerce una gran influencia en su vida interna, sin que, por el momento, se perfilen contrapesos en su seno. Además, si bien no es un partido creado desde el gobierno, llega al gobierno antes de estar consolidado.

Todo ello plantea interrogantes en cuanto a su autonomía organizacional, su proceso de institucionalización y su propia capacidad de asumir su situación de dominio tal como pudo observarse en los incipientes y caóticos intentos de re- 
novación de su dirigencia en el otoño de 2019. En cuanto a su entorno, habrá que ver qué sucede con la legislación electoral y cómo se va a dar el proceso de reconstrucción de la oposición al gobierno. Si algo es seguro es que las condiciones para la reinstauración del sistema de partidos que había de 1990 a 2018 ya no existen.

\section{BibLIOGRAFÍA}

"Agustín Basave es el nuevo dirigente nacional del PRD”, Animal Político, 7 de noviembre de 2015, https://www.animalpolitico. com/2015/11/agustin-basave-es-el-nuevo-dirigente-nacionaldel-prd/

Alarcón Olguín, Víctor, "Democracia interna y selección de candidatos presidenciales en México. De la simulación a la competencia”, Flavia Freidenberg y Manuel Alcántara Sáez (eds.), Selección de candidatos, política partidista y rendimiento democrático, México, Universidad de Salamanca-Universidad Nacional Autónoma de México-Tribunal Electoral del Distrito Federal, 2009.

Alcántara, Suzzete "Ricardo Anaya toma protesta como candidato de la coalición Por México al Frente", Ciudad de México, 18 de febrero 2018, https://www.eluniversal.com.mx/eleccio nes-2018/ricardo-anaya-toma-protesta-como-candidato-de-lacoalicion-por-mexico-al-frente

Alcocer V. Jorge, "La regulación de los partidos políticos", Lorenzo Córdova y Pedro Salazar (coords.), Estudios sobre la reforma electoral 2007. Hacia un nuevo modelo, México, Tribunal Electoral del Poder Judicial de la Federación, 2008.

"Alejandra Barrales, nueva presidenta del PRD", El Economista, 16 de julio de 2016, https:/ / www.eleconomista.com.mx/politica/Ale jandra-Barrales-nueva-presidenta-del-PRD-20160716-0009.html

Beauregard, Luis Pablo, "El PAN y PRD apuestan por aliarse para vencer al PRI en las elecciones”, El País, 4 de febrero de 2016, https://elpais.com/internacional/2016/02/04/mexico/1454 609543_900363.html 
"Consejo del PRD aprueba ir en coalición con PAN y Movimiento Ciudadano en 2018", Animal Político, 19 de noviembre de 2017, https:/ /www.animalpolitico.com/2017/11/prd-coalicionelecciones-2018/

"Desdeña PAn a Margarita Zavala”, Milenio, 12 de enero de 2015, https://www.milenio.com/politica/desdena-pan-a-margaritazavala

"El PRI reconoce su derrota electoral, mientras el PAN destaca sus victorias históricas", Animal Político, 6 de junio de 2016, https:/ / www.animalpolitico.com/2016/06/lideres-del-pri-pan-y-prdpresumen-sus-ventajas-electorales-en-la-jornada-del-5-dejunio/

"Elección en el PAN: Ricardo Anaya gana y será el nuevo dirigente nacional", Animal Político, 16 de agosto de 2015, https://www. animalpolitico.com/2015/08/inicia-la-eleccion-de-dirigentenacional-del-pan/

Fundar, Fue un mal año. No, menos como seis, México, noviembre de 2018.

GARCíA, Ariadna, "Instala PRI Comisión para procesos internos al 2018”, El Universal, 22 de noviembre de 2017, https://www.elu niversal.com.mx/nacion/politica/instala-pri-comision-paraprocesos-internos-al-2018

"Gobernadores del PAn piden alianza para Edomex", Milenio, 21 de diciembre de 2016, https://www.milenio.com/politica/gober nadores-del-pan-piden-alianza-para-edomex

GonzÁlez, Isabel, "Agustín Basave renuncia a la dirigencia del PRD”, Excélsior, 18 de junio de 2016, https:/ / www.excelsior.com. $\mathrm{mx} /$ nacional/2016/06/18/1099610

Gutiérrez, Héctor y Magali JuÁrez, “PAN, PRD y MC formalizan ante el InE alianza electoral”, 5 de septiembre de 2017, https:/ / www.elfinanciero.com.mx/nacional/pan-prd-y-mc-presentanel-frente-ciudadano-por-mexico

Guzmán, Susana y Héctor Gutiérrez, "Surge nueva corriente en el PRD: Militantes de izquierda", El Financiero, 14 de diciembre de 2016, https://www.elfinanciero.com.mx/nacional/surgenueva-corriente-en-el-prd-militantes-de-izquierda 
GuZMÁn, Susana, "Padierna llama a la rebelión en el PRD por posible alianza con AN", El Financiero, 27 de junio de 2017, https:/ / www.excelsior.com.mx/nacional/2017/03/29/1154690

Hernández de Gante, Alicia y Adrián Gimate-Welsh, "El debate legislativo en torno al umbral electoral en la reforma político electoral de 2013-2014", Revista Mexicana de Ciencias Políticas y Sociales 52, núm. 232.

Hernández, Rogelio y Will G. Pansters, "La democracia en México y el regreso del PRI”, Foro Internacional 52, 210, 2012.

Hernández, Rogelio, "El refugio del PRI durante la alternancia panista”, Foro Internacional 55, núm. 219, 2015.

Huntington, Samuel, Political Order in Changing Societies, New Haven y Londres, Yale University Press, 1969.

Lawson, Kay, "When Linkages Fails", Kay Lawson y Peter Merkl (eds.), When Parties Fail: Emerging Alternative Organizations, Princeton, University Press, 1988.

LunA, Fernando, "Morena: La formación de un partido político y sus primeros rasgos organizativos", tesis de Maestría en Ciencia Política, México, Centro de Estudios Internacionales, El Colegio de México, 2018.

Mainwaring, Scott, Rethinking Party Systems in the Third Wave of Democratization: The Case of Brazil, Stanford, University Press, 1999.

MaIr, Peter, Party System Change: Approaches and Interpretations, Oxford, Clarendon Press, 1997.

"Manlio Fabio Beltrones renuncia a dirigencia del PRI", Milenio, 20 de junio de 2016, https:/ / www.milenio.com/politica/manliofabio-beltrones-renuncia-dirigencia-pri

Marcial Pérez, David, "Morena vuelve a golpear en Ciudad de México pero no tumba al PRD”, El País, 6 de junio de 2016, https:/ /www.sinembargo.mx/21-01-2016/1602799

"Margarita Zavala deja el PAN y culpa a Anaya", Sin Embargo, 6 de octubre de 2017, https:/ / www.sinembargo.mx/06-10-2017/332 3534

"Margarita Zavala destapa ambición presidencial para 2018”, Excélsior, 14 de junio de 2015, https://www.excelsior.com.mx/nacio $\mathrm{nal} / 2015 / 06 / 14 / 1029450$ 
"Meade dice que él decidió quitar a Ochoa la dirigencia del PRI y que hará más ajustes en su campaña”, Animal Político, 3 de mayo de 2018, https://www.animalpolitico.com/2018/05/meadeochoa-cambio-campana/

Mercado, Angélica, "Zoé Robledo se baja de contienda por PRD”, Milenio, 5 de noviembre de 2015, https://www.milenio.com/ politica/zoe-robledo-se-baja-de-contienda-por-prd

Montalvo, Tania L., "2016, el año de la derrota histórica del PRI en elecciones estatales", Animal Político, 7 de junio de 2016, https:/ /www.animalpolitico.com/2016/06/2016-el-ano-de-laderrota-historica-del-pri-en-elecciones-estatales/

Prud'homme, Jean-François, "El Partido Acción Nacional y el Partido de la Revolución Democrática después de las elecciones de 2012”, en Arturo Alvarado (coord.), Elecciones en México: cambios, permanencias y retos, México, El Colegio de México, 2016.

Prud'homme, Jean-François, "El sistema de partidos" en Soledad Loaeza y Jean-François Prud'homme (coords.), Instituciones y procesos políticos, México, El Colegio de México, 2010.

Robles de la Rosa, Leticia, "El PRD se desmorona en el Senado; abandonan 12 la bancada”, Excélsior, 29 de marzo de 2017, https://www.excelsior.com.mx/nacional/2017/03/29/11 54690

Robles DE lA Rosa, Leticia, "El PRI analiza causas de las derrotas; investiga posible traición”, Excélsior, 9 de junio de 2016, https:/ / www.excelsior.com.mx/nacional/2016/06/09/1097697

Robles DE LA Rosa, Leticia, "PRI logra 2.65 millones de votos; le sigue Morena; Edomex, nicho electoral del tricolor”, Excélsior, 6 de junio de 2017, https://www.excelsior.com.mx/nacional/ 2017/06/06/1167998

RoldÁn, Nayeli, "El PRI regresa a gobernar Oaxaca: Alejandro Murat es puntero en los resultados", Animal Político, 6 de junio de 2016, https:/ /www.animalpolitico.com/2016/06/el-pri-regre sa-a-gobernar-oaxaca-alejandro-murat-es-puntero-en-los-resul tados/

RosAgEl, Shaila, "El PRD cumple 26 años sin 30 de sus líderes más importantes, sin festejo y en silencio", Sin Embargo, 5 de mayo de 2015, https:/ / www.sinembargo.mx/05-05-2015/1334261 
RosAgel, Shaila, "Tribus del PRD pelean por poder, no por ideología: analistas; 15 grupos guerrean por liderazgo", Sin Embargo, 21 de enero de 2016, https:/ / www.sinembargo.mx/21-01-2016/ 1602799

Sartori, Giovanni, Partidos y Sistemas de Partidos. Madrid, Alianza Editorial, 2005.

"Silvano Aureoles y Graco Ramírez alzan la mano y van por la candidatura presidencial del PRD", Animal Político, 2 de marzo de 2017, https:/ /www.animalpolitico.com/2017/03/silvano-gracocandidatura-prd / 